




\section{ARTICLE XII.}

On the Storm which was experienced throughout the Uniled States about the 20th of December, 1836. By Elias Loomis, Professor of Mathematics and Natural Philosophy in Western Reserve College. Read March 20, 1840.

BeIng well convinced that meteorology is to be promoted, not so much by taking the mean of long-continued observations, as by studying the phenomena of particular storms developed over a widely extended country, I resolved to select some single storm of strongly marked characteristics, and trace its progress as extensively and minutely as possible. For this investigation I made choice of the storm which occurred in the United States about the 20th of December, 1836; not only because it seems well suited to my purpose, but because I found ready furnished for my use a considerable number of most valuable observations. In the eastern states this storm occurred within the period recommended by Sir John Herschel for hourly meteorological observations, and all the phenomena of the storm were most carefully and minutely recorded at eight different stations, namely, at Baltimore, New York, Albany, Flushing, New Haven and Gardiner, in the United States; as, also, at Montreal and Quebec, in Lower Canada. These observations, with the exception of those at Baltimore, are published in the Report of the New York University Register for 1837. I addressed a letter to each individual who, so far as I could ascertain, kept a meteorological register, requesting an extract from the same for the period in question. The result is that I have obtained barometric observations from twenty-seven different stations within the United States and VII -2 G 
the neighbouring British possessions. The situation of these stations, and the authority upon which the observations rest, are shown in the following table:

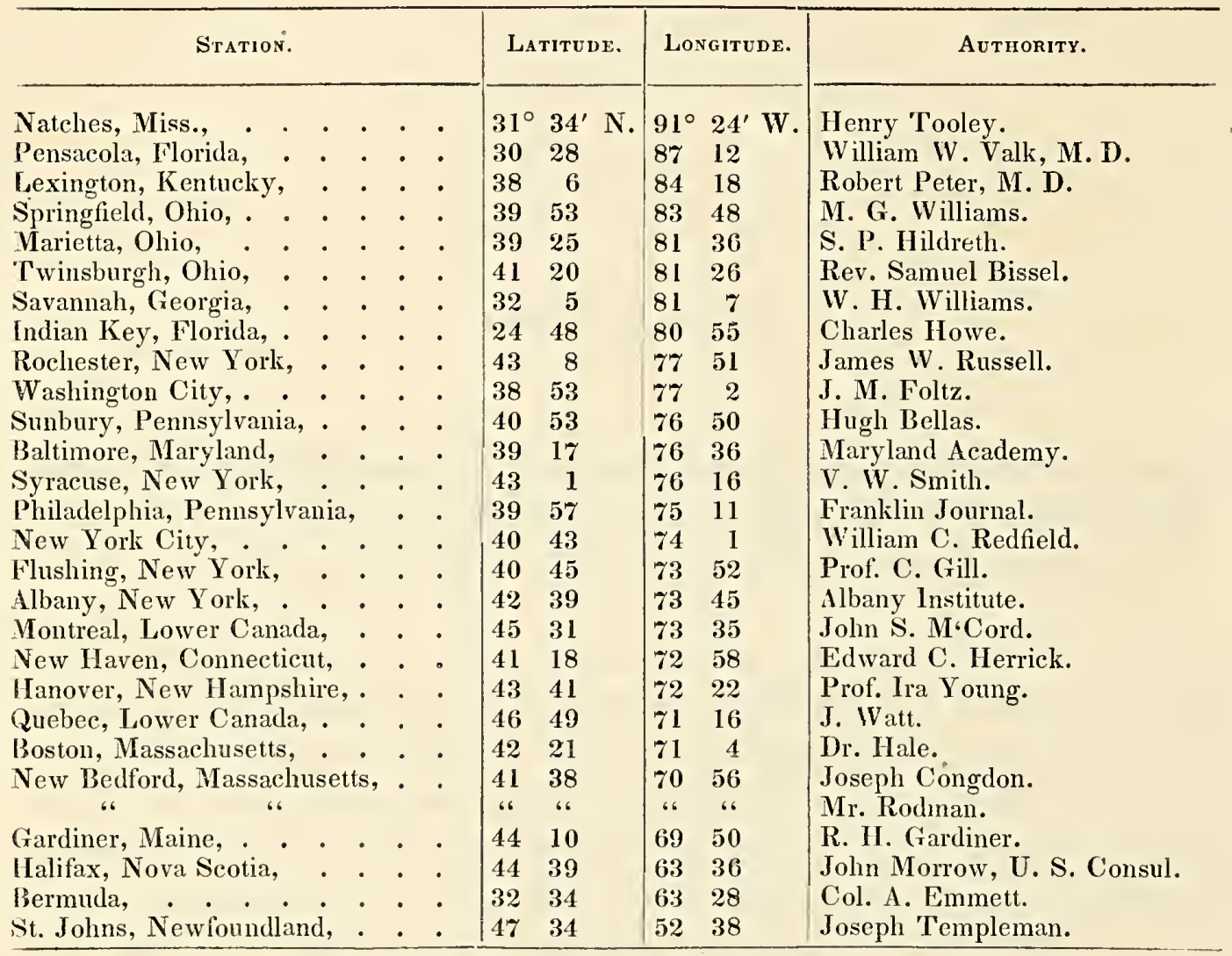

I have been more successful in obtaining meteorological registers which did not comprise observations of the barometer. Through the politeness of Hon. Elisha Whittlesey, late Representative in Congress, I have obtained a copy of the observations made at the different military stations of the United States; and through Mr. M. H. Webster, of Albany, N.Y., I have obtained a copy of the observations made at the several academies in the State of New York. To Messrs. S. C. Walker, E. C. Herrick, and S. F. Plimpton, I am under particular obligations for their assistance in obtaining for me meteorological journals.

The following table shows the names and situations of the military posts from which observations have been received. 


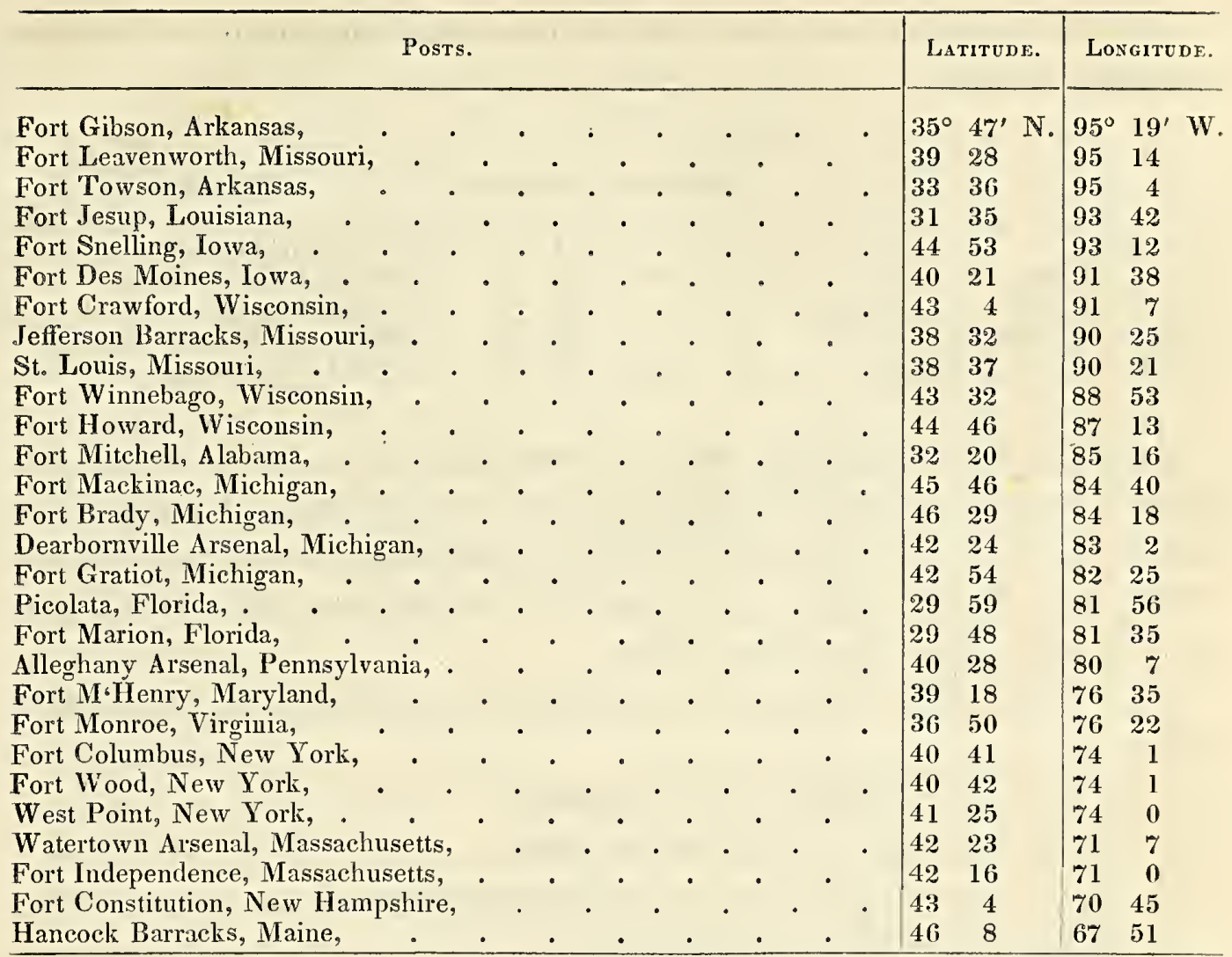

The following table shows the situation of the academies in New York from which observations have been obtained.

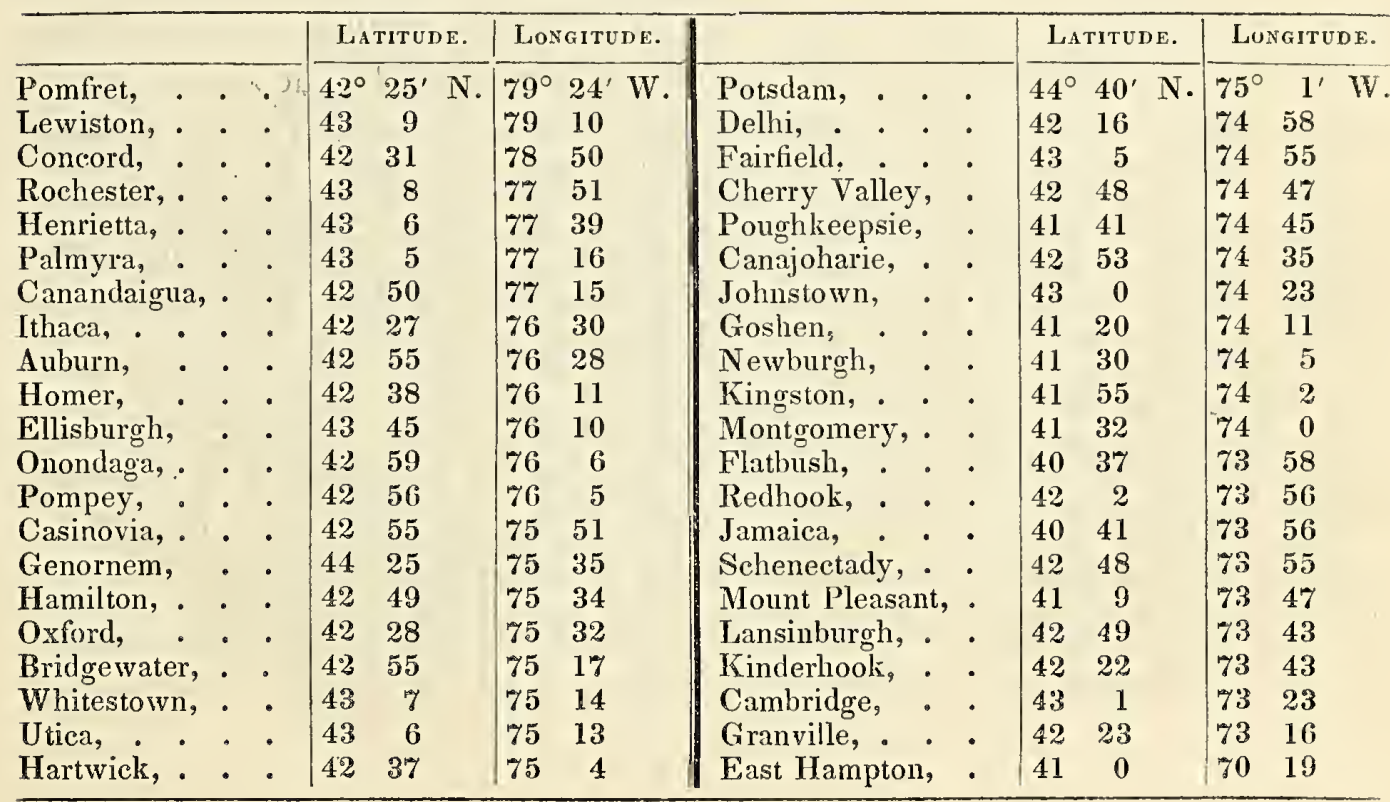


The following are the additional stations from which meteorological registers have been received.

\begin{tabular}{|c|c|c|c|c|c|}
\hline & & & Latitude. & LONGITUDE. & AUTHORITY. \\
\hline $\begin{array}{l}\text { Baton Rouge, : } \cdot \text {. } \\
\text { Augusta, Illinois, : } \\
\text { St. Louis, Missouri, : } \\
\text { St. Augustine, Florida, } \\
\text { Charleston, South Carolina, }\end{array}$ & $: \dot{:}$ & $\dot{:}$ & $\begin{array}{lll}30^{\circ} & 28^{\prime} & \mathrm{N} \\
40 & 15 & \\
38 & 37 & \\
29 & 48 \\
32 & 46\end{array}$ & $\left|\begin{array}{cc}91^{\circ} & 28^{\prime} \\
91 & \mathbf{W} \\
90 & 21 \\
81 & 55 \\
79 & 57\end{array}\right|$ & $\begin{array}{l}\text { Surgeon of Penitentiary. } \\
\text { Samuel B. Mead, M. D, } \\
\text { George Engelmann, M.D. } \\
\text { Surgeon of Military Hospital. } \\
\text { Prof. C. U. Shepard. }\end{array}$ \\
\hline
\end{tabular}

I have also collected a great variety of observations from stations beyond the probable limits of the storm, to which reference will be made in the sequel. I think it unnecessary to transcribe all the above mentioned observations at large, because they would occupy a great space, and the substance of them will presently be presented in a condensed form.

In discussing these observations, four distinct subjects of inquiry present themselves.

I. A remarkable oscillation of the barometer.

II. A sudden depression of the thermometer.

III. Rain-amount-with time of beginning and end.

IV. Wind-its duration and velocity.

I. The oscillation of the barometer.

A bare inspection of the meteorological registers is sufficient to show that during the period in question there was every where throughout the United States a sudden depression of the barometer, immediately succeeded by an equally sudden rise; that the barometric minimum occurred first in the western states, and later in the eastern, passing like a wave over the entire country, from west to east. In order to present this fact in the most striking light, I have projected on Plate I., Fig. 1, curves representing this oscillation of the barometer at each station. The abscissas represent the times of observation, and the ordinates the barometric heights on a scale reduced one-third; that is, a difference of two-thirds of an inch in the ordinates of a curve is intended to show an absolute oscillation of the barometer to the amount of an inch. It will be observed that at most of the stations there is a striking resemblance in the curve described, so that we need not hesitate to call it the same wave; just as an elevation or depression of the surface of the ocean which arrives. 
successively at distant stations, we call one wave, understanding, of course, that the same wave, at successive instants, may be formed by entirely different particles of water. The same atmospheric wave, then, passed over the continent from west to east, from the valley of the Mississippi to the Bermudas and Newfoundland. We wish now to be able to assign the rate of progress of this wave, and in order to institute the comparison, we must fix upon some particular phase of the wave. We might make the comparison for the times of either the barometric maximum or minimum. The latter, however, is much the best suited to our purpose, as the barometer remained much longer near the high than the low extreme. There is a difficulty, however, in ascertaining the precise instant of even the barometric minimum. When observations are taken but two or three times a day, it is highly improbable that the minimum should occur at the precise instant of either observation. There may, therefore, be an uncertainty in the time to the amount of twelve hours, or more. Fortunately, however, this uncertainty is, in a measure, obviated in the present instance. The hourly observations made at Baltimore, Montreal, Albany, Flushing, New Haven and Gardiner, exhibit the precise form of the barometric curve described, and the instant of greatest depression. Moreover, as will appear in the sequel, this minimum was contermporaneous with a remarkable change of wind, and the time of this change was noted at several stations; as, for example, at Springfield, Syracuse, Philadelphia, New York, and Hanover. At nearly half of the stations, then, the time of minimum is certainly known; and the form of the curve at these stations will guide us in completing the curve at the remaining stations. This conjectural completion of the curves is represented on the chart by dotted lines. We are then enabled to trace the progress of this wave with very considerable precision. I accordingly drew upon a map of the United States lines connecting all those places where the barometer attained its minimum at the same instant. The result is shown on the accompanying chart, which exhibits the lines of greatest depression for every six hours from the morning of December 20th to the noon of the 23d. The velocity of the wave appears not to have been uniform. Thus, on the southern border of the United States its velocity varied from seventeen to twenty-nine statute miles per hour; and on the northern borders from seventeen to thirty-seven miles per hour. No allowance is here VII. $-2 \mathrm{HI}$ 
made for difference of longitude, which would increase this velocity by about one twenty-fifth part. The form of these curves for the north-west part of the United States rests mainly upon the thermometric observations to be described presently. The front of this wave appears, in many places, decidedly convex, to an amount much beyond the possible errors of observation.

Having thus discovered the form and velocity of the wave, let us attend to the amount of the depression of the barometer. The following table exhibits the difference between the barometric minimum and the subsequent maximum, the observations being arranged in the order of latitude.

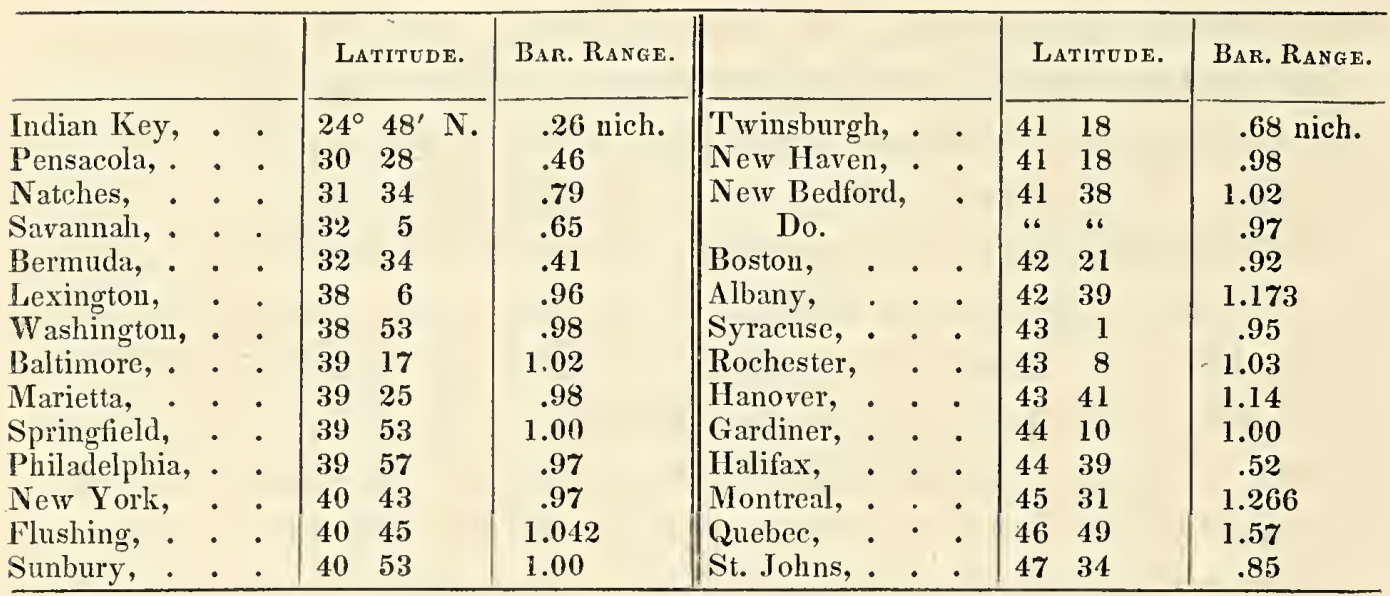

It will be observed that the range of the barometer increases generally with the latitude. A more particular consideration of the subject, however, is deferred for the present. I come, therefore, to consider,

II. The movement of the thermometer.

The movement of the thermometer during the period in question was quite as remarkable as that of the barometer, and generally in the opposite direction. Thus, while the barometer was falling under the influence of the storm, the thermometer was every where rising; and as the barometer rose the thermometer fell with extraordinary rapidity. It is not thought necessary to insert here all the observations which have been collected. The following, being about half the whole number, are selected as being, from their distribution, a fair representative of the whole. 
ABOUT THE 20TH OF DECEMBER, 1836.

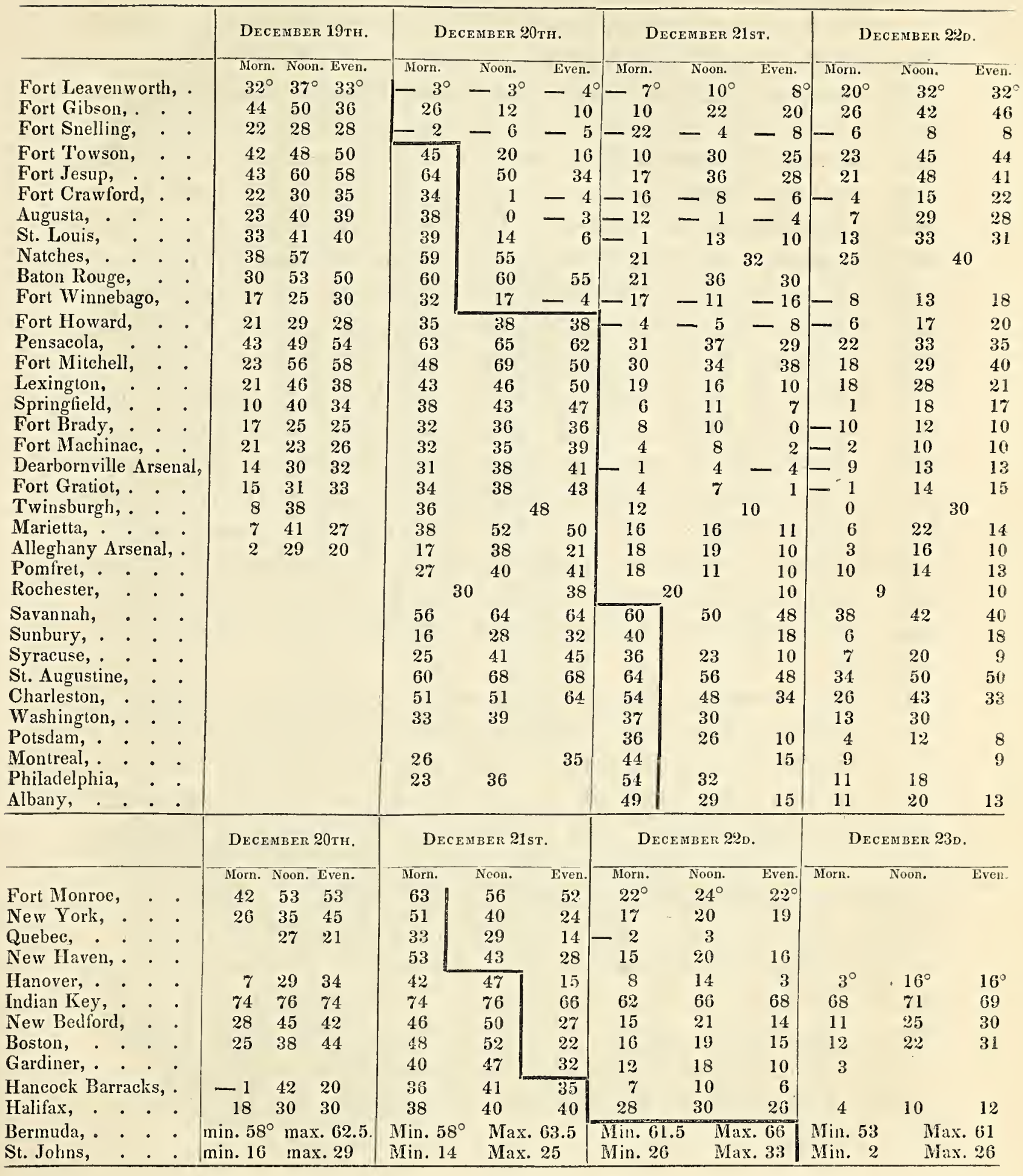


The fall of the thermometer is very sensible in all of the observations, and the instant of change $\mathrm{I}$ have indicated by a dark line drawn across the table. The observations at the military posts were made at 7, A. M.; 2 and 9, P. M.; and the others were generally made about the same hours. It is not easy to compare, with entire precision, the rate or amount of the depression of the thermometer at the several stations, because the change occurring at different hours is variously affected by the diurnal change of temperature. A correction needs to be applied for this inequality before the observations are comparable, and this correction it is difficult to apply with entire satisfaction. It requires, however, but a hasty inspection of the table to perceive that the depression of the thermometer was greater in the northern than the southern states, and greater in the western than the eastern; that is, the fall was most remarkable of all in the north-western states. Thus, for example, at Fort Crawford, from the morning of the 20th to that of the 21st, at the same hour, the thermometer fell $50^{\circ}$; at Augusta the same, and at Fort Winnebago $49^{\circ}$. At Augusta, on the 20 th, the thermometer fell $38^{\circ}$ from sunrise to 2, P. M., that is, against the diurnal variation, which, according to observations made at the same place for the entire month, amounts to ten degrees; making the real depression of the thermometer forty-eight degrees in six and a half hours, the most remarkable fluctuation I recollect ever to have heard of; and this, too, in a latitude south of Naples.

The commencement of this depression coincided sensibly with the minimum of the barometer. This is very satisfactorily shown by the hourly observations. In a few instances the thermometer fell a degree or two before the barometric minimum; but in all cases the fall of the thermometer became very rapid after the barometer began to rise. This appears to be a well established feature of the storm, and I have availed myself of it in tracing the progress of the storm in regions where barometric observations could not be obtained. This was particularly true of the north-west part of the United States, and I have projected on Plate I., Fig. 2, the observations made in this region in the same manner as the curves on Plate I., Fig. 1, were constructed. The observations were first corrected for the diurnal inequality. The curves exhibit to some extent the effect of local causes; although, on the whole, the resemblance is quite striking, and probably would have been still more so if the observations had been made at shorter intervals. 
In order to determine the dependence of the temperature upon latitude and longitude, I classified the observations as below, placing the most western observations on the left and the eastern on the right, and arranging each in the order of latitude. The table shows the greatest heat observed during the storm, and the greatest cold immediately succeeding it.

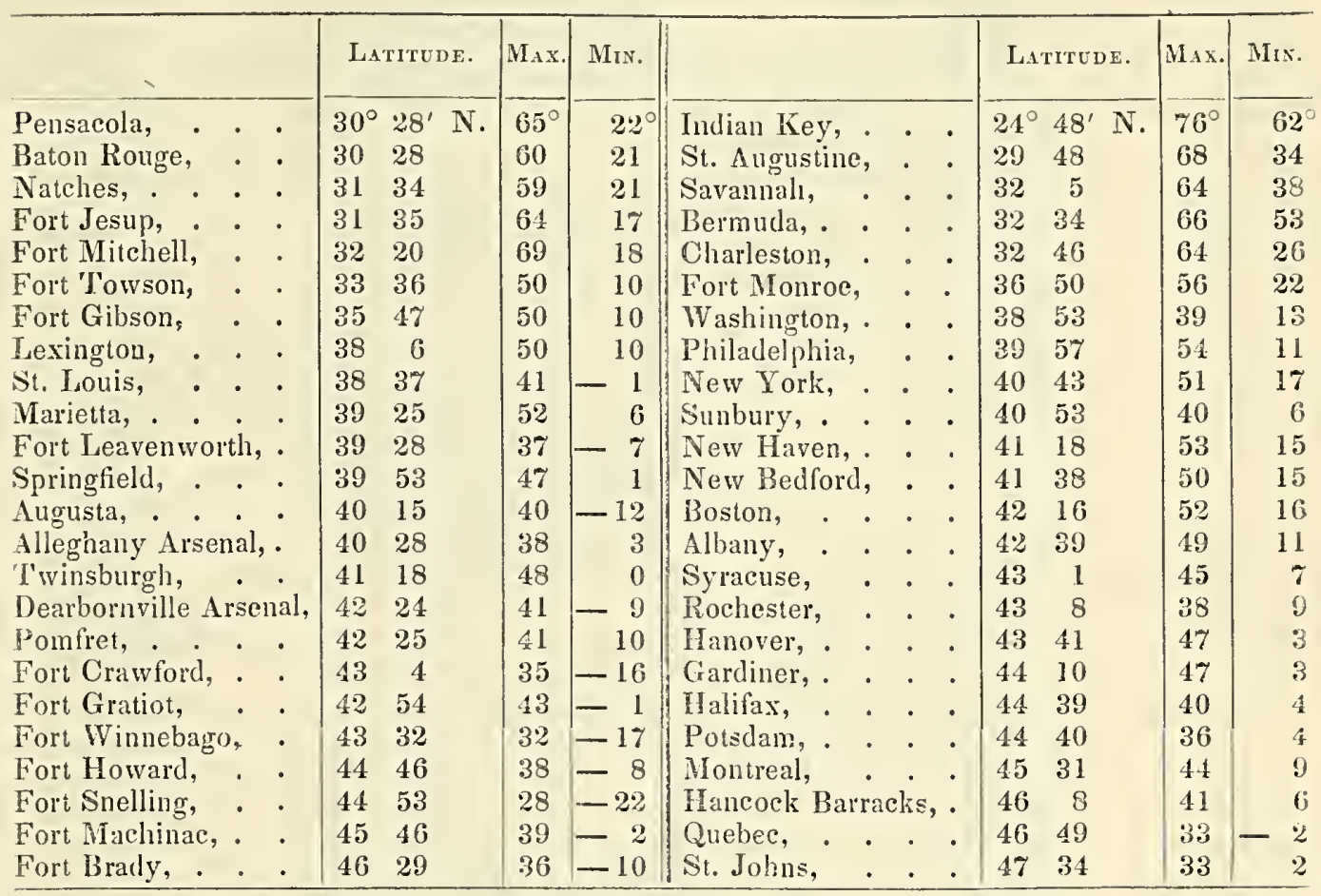

The average of the maxima at the eastern stations is about three and a half degrees greater than at the western; and the average of the minima fourteen degrees greater. It is remarkable that, with the exception of Quebec, the only stations where the thermometer fell below zero were in the north-west quarter of the United States, and would be cut off by a line joining Detroit and St. Louis.

III. Rain-amount, \&c.

The following table shows the amount of rain which fell at the different stations, with the time of commencement and termination, so far as the same could be collected from the registers.

$$
\text { VII-2 I }
$$




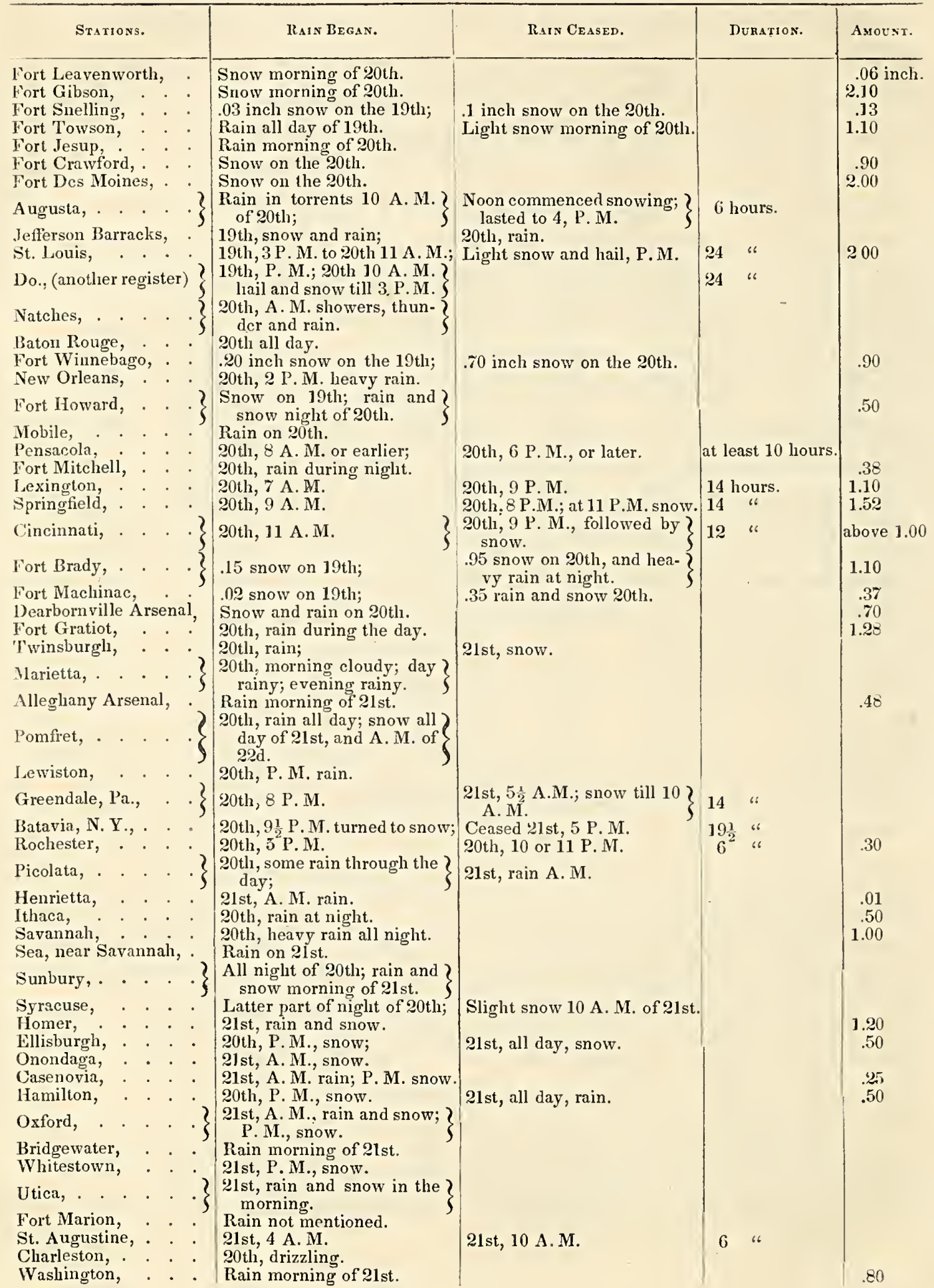




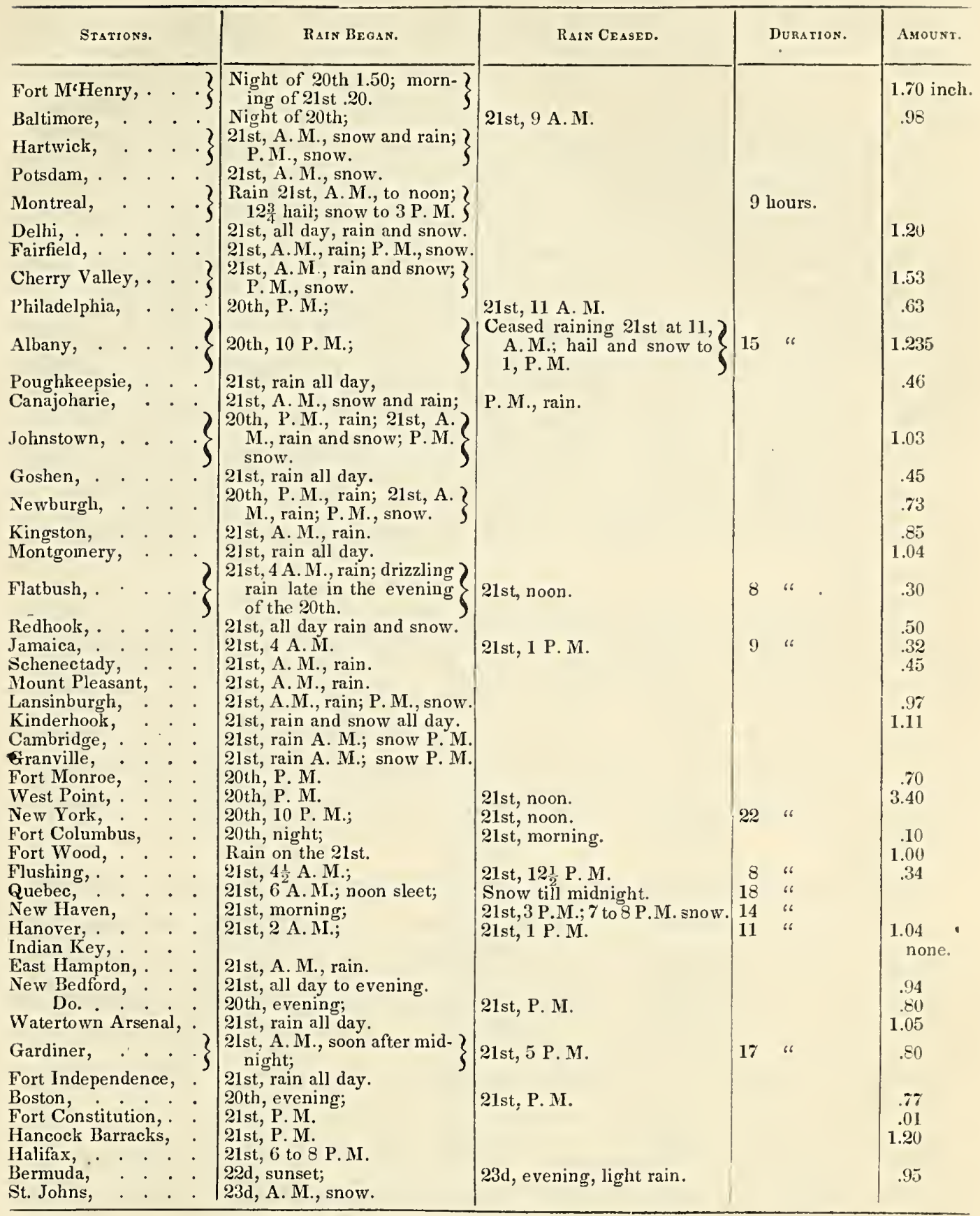

It will be observed that rain or snow fell at every one of the above stations except Indian Key, an island south of Florida. The rain, then, extended from 
about latitude $28^{\circ}$ to latitude $48^{\circ}$, and from longitude $52^{\circ}$ to $96^{\circ}$. How much farther it extended will be a subject of future inquiry. Throughout all this region the rain was very abundant. The average at the fifty-nine stations where the amount is given is about seven-eighths of an inch. This, then, may be taken as the probable average depth of the rain throughout the United States. This amount, however, was far from being the same at all places. The greatest amount fell at West Point; and at three other stations, Fort Gibson, Fort Des Moines, and St. Louis, the amount was two inches, or more. On the other hand, at a few stations, the amount given is exceedingly small. Thus, at Henrietta and Fort Constitution, it is stated at 0.01 inch. I think it probable there is here a mistake in the decimal point, and that the numbers should read one-tenth inch, or, perhaps, even one inch. I have myself consulted the copy of the observations preserved at Washington, and find that the total of rain for the month, at Fort Constitution, is greater than the sum of all the items shown in the register. Some mistake was probably committed in transcribing:

It may, also, fairly be presumed there was some defect in the rain-gauge used at West Point. According to the register, the amount of rain for nine months of the year 1836 was 73.27 inches. During the other three months the gauge was not observed. Making, however, a proportionate allowance for this period, we have the annual amount of rain 97.69 inches. The average amount of rain for the state of New York, as appears by the Regent's Reports, is 36 inches.

The stations at which much or little rain fell appear scattered indiscriminately over the country, so that it is difficult to say in what district rain was most abundant. The amount at stations moderately removed from each other was very unequal. Thus, while at West Point the amount is stated at 3.40 inches, at Montgomery, seventeen miles north-west, it was 1.04; at Newburgh, eight miles north, it was $.73 \mathrm{inch}$; at Poughkeepsie, twenty-two miles north, .46 inch; and at Goshen, eighteen miles west, .45 inch. So, also, at Fort Wood, in New York harbour, the amount was one inch, while, at Fort Columbus, in the same harbour, it was 0.10 inch; and at Flushing, Jamaica, and Flatbush, (all within fifteen miles,) the amount at each place was about one-third of an inch. Also at Fort Brady the amount was 1.10 inch, while, at Tort Mackinac, not fifty miles distant, it was but .37 inch. These inequalities may probably, 
in part, be ascribed to errors of observation, to defective gauges, or improper exposure, yet the differences are too considerable and numerous to be wholly disposed of in this summary way.

Most of the registers are very defective in not naming the hour when the rain commenced or ceased. Some of the accounts, however, are sufficiently precise; and by comparing all the observations, it is believed that the limits of the rain for any particular instant may be determined with considerable confidence. I have drawn upon the accompanying chart a line representing the limit of rain for midnight of the 20th-21st. The curve representing the western limit corresponds closely to the curve of barometric minimum, but the curve of the eastern limit differs sensibly from it. It will be observed I make no distinction here between rain and snow. At the southern stations only rain fell; at some of the northern only snow; while, at the intermediate points, there fell both rain and snow. Both are probably to be ascribed to the same cause.

IV. Wind-direction and force.

The following table shows the direction of the wind at each station of observation. The letters underlined indicate strong winds. A double line indicates a gale. At but a few of the stations was the strength of the wind noted.

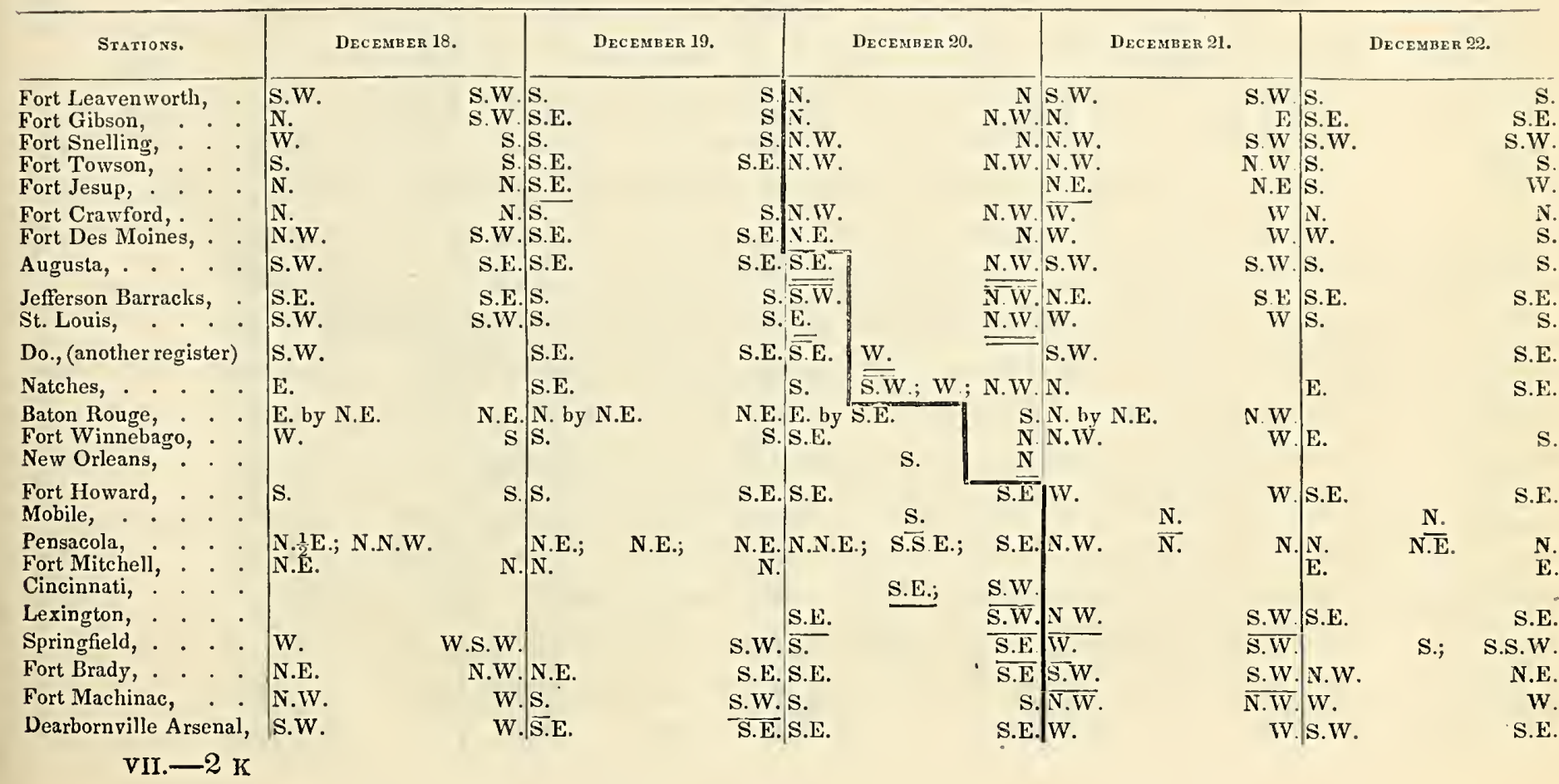




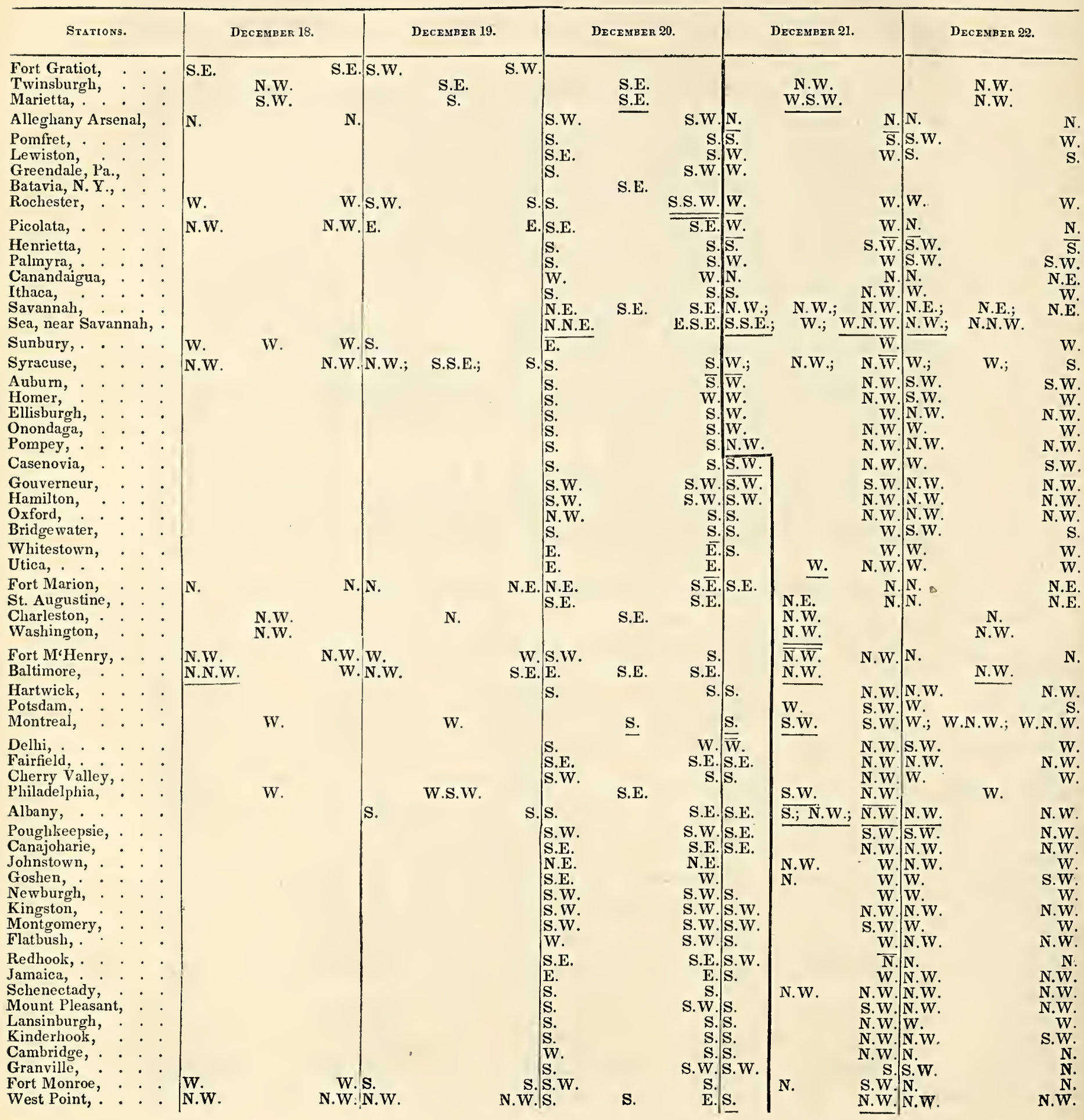




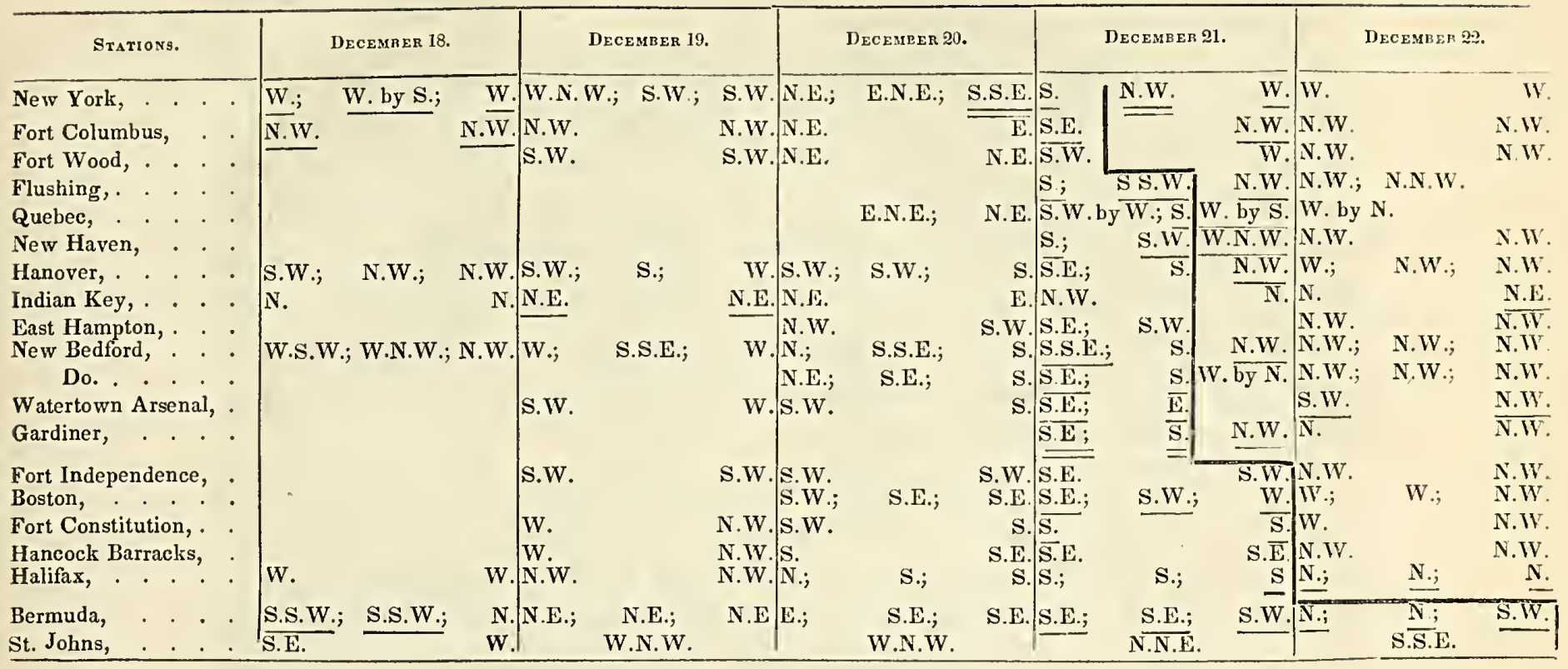

At Bermuda, on the 23d, the wind was N.; N. N. E.; E. N. E.; and at St. Johns, N. N. W. I have drawn a dark line across the preceding table, representing the time of the barometric minimum. It will be observed that this crisis was marked by an extraordinary change of wind. Thus, at almost every station in the table, the wind, for nearly a day before the crisis, blew from the southern quarter, generally for several hours from the south-east. This southeast wind is believed to have been more general than the table would seem to indicate; because, not being of long continuance, it did not, at every station, happen to blow at either of the fixed hours of observation. This crisis was as uniformly followed by a wind from nearly the opposite quarter; commonly the north-west. This sudden change of wind, then, was every where one of the most prominent features of the storm. The wind, before the change, is characterized by the terms high—strong-windy-brisk-fresh-very high-violent-gale-severe gale. It would seem to have been most severe at New York, and places farther east. After the change, it is characterized by the terms high-very windy-violent-blustering-hard violent—strong gusts-strong gale-tremendous gale-one of the most violent gales ever experienced. From which it would appear that the wind was generally more violent after than 
before the change; though, perliaps, the reverse was the case at New York City, and throughout New England.

I have now presented the most important facts which I have been able to collect respecting the storm in question. Its principal characteristics were as follow:-After a cold and clear interval, with barometer high, the wind commenced blowing from the south. The barometer fell rapidly, the thermometer rose-rain descended in abundance. The wind veered suddenly to north-west, and blew with great viclence; the rain is succeeded by hail or snow, which continues but a short time; the barometer rises rapidly; the thermometer sinks as rapidly. These changes are experienced not every where simultaneously, but progressively from west to east.

Before proceeding to analyze these facts more particularly, it may be well to inquire for the probable limits of the storm. This question is not merely curious, but will be seen to be intimately connected with the rationale of the phenomena. By inspecting Plate I., Fig. 1, it will be seen that the oscillation of the barometer was every where quite marked, except at Indian Key. It should be stated that the observations at this place were made with a sympiesometer, an instrument far less satisfactory than the mercurial barometer. Here the range was only a quarter of an inch, and the curve described bears very little resemblance to those at the other stations. I am inclined, however, to consider this slight change of pressure as due to the same causes as the greater oscillation in higher latitudes. No rain fell at this station. This, then, was beyond the limit of rain, and the barometer and thermometer were but slightly affected. In Senate Documents, No. 300, 1838, are given observations of the thermometer at Santa Cruz, Latitude $17^{\circ} 45^{\prime} \mathrm{N}$., Longitude $64^{\circ} 35^{\prime} \mathrm{W}$., for December, 1836. The mean of observations taken six times a day gave, December 15th, $76^{\circ} .2 ; 16$ th, $77^{\circ} .5 ; 17$ th, $78^{\circ} .1 ; 18$ th, $78^{\circ} .7 ; 19$ th, $77^{\circ} .9 ; 20$ th, $77^{\circ} .2 ; 21$ st, $77^{\circ} .4$; $22 \mathrm{~d}, 76^{\circ} .6 ; 23 \mathrm{~d}, 75^{\circ} .2 ; 24$ th, $75^{\circ} .9 ; 25$ th, $74^{\circ} .7 ; 26$ th, $75^{\circ} .0 ; 27$ th, $74^{\circ} .4 ; 28$ th, $75^{\circ} .6 ; 29$ th, $75^{\circ} .1$.

The temperature was exceedingly uniform during this whole period, yet it will be observed there was a slight fall of the thermometer on the 23d. This is about the time that the cold wave which passed over the United States might be expected to be felt there, if felt at all. No other particulars respecting the weather are stated, except the general remark that "frequent small showers 
fell during the month, but no one which continued longer than from five to ten minutes." Santa Cruz, then, may be considered as beyond the limits of the storm, though, perhaps, not wholly beyond its sensible influence.

The following is extracted from the journal of the ships Mary and Susan, bound from Calcutta to New York:-

\begin{tabular}{|c|c|c|c|c|c|}
\hline Dec. 22, & $\begin{array}{l}\text { Latitude. } \\
8^{\circ} 56^{\prime} \mathrm{N} \text {. }\end{array}$ & $\begin{array}{l}\text { Longitude. } \\
44^{\circ} 36^{\prime} \mathrm{W} \text {. }\end{array}$ & $\begin{array}{l}\text { Barometer. } \\
\quad 28.58\end{array}$ & $\begin{array}{l}\text { Thermometer. } \\
79^{\circ}\end{array}$ & $\begin{array}{c}\text { Wind. } \\
\text { N. E., light and variable. }\end{array}$ \\
\hline 23 & $9 \quad 43$ & $45 \quad 41$ & .59 & 78 & N. E., " " " \\
\hline 24 , & 1041 & 57 & .60 & 78 & N., light and steady. \\
\hline 25 , & 11 & 19 & .60 & 79 & N. W. by W. \\
\hline 26 & 12 & 50 & .50 & 79 & Variable-calm. \\
\hline 27, & 34 & 22 & .56 & 78 & Variable-calm. \\
\hline 28, & 28 & 50 & .60 & 77 & Variable-calm. \\
\hline
\end{tabular}

It will be observed that the barometer was lowest on the 26th; and this is about the time that the wave which passed over the United States might be expected here, if felt at all.

I have obtained from the navy department at Washington a copy of the Meteorological Journal of the United States ship Peacock, for December, 1836. The greatest height of the barometer during the month was, on the 7th, 30.00 inches. Greatest depression, on the 18th, 29.88. Total range for the month, .12 inch. The ship was on the eastern coast of the Pacific, between latitude $16^{\circ} 50^{\prime} \mathrm{N}$. and latitude $2^{\circ} 19^{\prime} \mathrm{S}$. The preceding range is little, if any, greater than the diurnal oscillation at the equator. The hour of observation is not stated, so that we cannot decide whether the observations are affected by the diurnal inequality. The following is an extract from the register:-

\begin{tabular}{|c|c|c|c|c|c|c|c|c|}
\hline & Latitude. & Longitude. & & ermome & & Barometer. & Wind. & Remarks. \\
\hline & & & $8, A . M$ & 2, P.M. & 6, P.M. & & & \\
\hline $\begin{array}{r}\text { Dec. } 16, \\
17, \\
18, \\
19, \\
20, \\
21, \\
22, \\
23, \\
24,\end{array}$ & 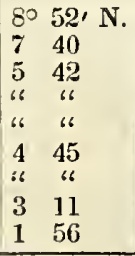 & $\begin{array}{lr}96^{\circ} & 34^{\prime} \\
96 & 49 \\
96 & 59 \\
97 & 3 \\
97 & 16 \\
97 & 4 \\
96 & 3 \\
94 & 23 \\
91 & 54\end{array}$ & $\begin{array}{l}78 \\
79 \\
79 \\
76 \\
74 \\
77 \\
77 \\
76 \\
74\end{array}$ & $\begin{array}{l}79 \\
80 \\
81 \\
80 \\
75 \\
78 \\
80 \\
77 \\
77\end{array}$ & $\begin{array}{l}77 \\
79 \\
78 \\
77 \\
75 \\
76 \\
78 \\
75 \\
76\end{array}$ & $\begin{array}{r}29.90 \\
90 \\
88 \\
90 \\
90 \\
90 \\
90 \\
90 \\
93\end{array}$ & $\begin{array}{l}\text { N. E. and East. } \\
\text { " " } \\
\text { North and East. } \\
\text { South and East. } \\
\text { Variable and calms. } \\
\text { "6 " " " " } \\
\text { " " } \\
\text { S. E. and South. }\end{array}$ & $\begin{array}{l}\text { Moderate and pleasant. } \\
\text { ": " } \\
\text { Squally, with rain. } \\
\text { Cloudy, with rain. } \\
\text { Slowers, pleasant. } \\
\text { "“ squally. } \\
\text { Pleasant. }\end{array}$ \\
\hline
\end{tabular}

VII-2 L 
Here is exhibited no oscillation of the barometer; but a mean depression of the thermometer, on the 20th, of three degrees from the 19 th, and $4^{\circ} .7$ from the 18th. This was simultaneous with the depression of the thermometer at the most western stations of the United States. It should be remembered, also, that although this fall of temperature was slight, it was considerable for the latitude. On the 19th the wind was south-east, with rain. The coincidence is certainly remarkable. Although, then, it seems not improbable that the causes which, in the United States, were operating with such energy, were sensible even in the vicinity of the equator, still, as there was no fall of the barometer, and the depression of the thermometer was but slight, we shall hesitate to call it the same storm, and shall fix upon the parallel of $25^{\circ} \mathrm{N}$. latitude as being not far from the southern limit of our storm. I have received a copy of the observations made on board the United States ship Erie, at Buenos Ayres, during the month of December, 1836, but it is impossible to identify any movement of the barometer from observations at a single station so remote.

The boundary on the west must be somewhat conjectural. At the rate with which the storm moved across the western states, it would have travelled from the Rocky Mountains to Fort Leavenworth in sixteen hours. The depression of the thermometer was more sudden and greater in amount at the western stations than in any other part of its observed course. No reason, then, can be seen why the storm should not have extended to the Rocky Mountains. But could it pass them? These mountains, in connexion with the Cordilleras, are understood to form a continuous range from the Frozen Ocean to the interior of Mexico, every where several thousand feet in elevation, and presenting insulated peaks, which, according to Professor Renwick, attain the height of twenty-five thousand feet above the sea. Suppose the warm south-east wind which was felt in the United States to blow over this wall covered with perpetual snow. The temperature of those elevated peaks during the month of December can hardly be supposed equal to zero of Fahrenheit. This warm current would then be suddenly cooled down to the temperature of that elevation, and its moisture be precipitated. The eastern side of the mountain would be buried in snow. Suppose the same air to continue its course and descend upon the other side of the range. It now comes into a warmer region; it brings with it only the moisture proper to an exceedingly low temperature; it is therefore a cold and dry wind, instead of a moist and warm one. Its cha- 
racter is wholly changed. It would seem, then, that even if the south-east wind could continue its course over this mountain barrier, it could carry no rain with it. So far, then, as rain, at least, is concerned, the Rocky Mountains must be supposed the western boundary of the storm.

I am unable even to conjecture a probable limit of the storm on the north. By inspecting the table on page 130 it will be seen that, with certain exceptions to be hereafter considered, the oscillation of the barometer increased pretty uniformly from the most southern to the most northern station. The range was greatest of all at Quebec. It would seem natural to infer that Quebec could not have been south of the centre of the storm. Why should not the storm have extended as far to the north as it did to the south of this station? On this supposition the northern limit would be found near the arctic circle. I have been unable to obtain observations of this date from any higher latitude in North America. As some guide, however, to my conjectures, I have instituted a comparison between the barometric observations made by Capt. Parry, at Melville Island in 1819-20, and similar observations made at New Haven. The following table exhibits the times and amount of all the barometric maxima observed at Melville Island which reached the height of 30.2 inches. Opposite these times I have given all the instances in which the barometer at New Haven rose to 30.1 inches within the ten days subsequent. I have also added another column, giving all the instances in which the barometer at London, by Professor Daniell's register, rose above 30 inches within the fifteen days subsequent.

\begin{tabular}{|c|c|c|c|c|c|c|c|c|c|c|c|c|c|}
\hline \multicolumn{3}{|c|}{ Melville Island. } & \multicolumn{5}{|c|}{ New Haven. } & \multicolumn{6}{|c|}{ LONDON. } \\
\hline April & 27 , & 30.86 & April & 29, & 30.27 . & $\begin{array}{l}\text { Interval } \\
\text { : }\end{array}$ & 2 day & May & 1, & 30.33. & $\begin{array}{l}\text { Interval } \\
\text { "6 }\end{array}$ & 40 & days. \\
\hline Jan. & 16 & .77 & Jan. & 21 & .22. & “ & 56 & Jan. & 22 & .07 & "6 & 6 & "6 \\
\hline & & & Jan. & 23. & .13 & “ & 76 & Jan. & 29 & .09 & "، & 13 & ، \\
\hline Dec. & 30 & .75 & * Jan. & 7 & .32 . & “ & 8 & $\begin{array}{l}* \text { * Jan. } \\
\text { Jan. }\end{array}$ & $\begin{array}{r}9, \\
14,\end{array}$ & $\begin{array}{l}.59 . \\
.12 .\end{array}$ & "6 & $\begin{array}{l}10 \\
15\end{array}$ & “" \\
\hline Sept. & 3 , & .42 & $\begin{array}{l}\text { Sept. } \\
\text { * Sept. }\end{array}$ & $\begin{array}{r}6 \\
12\end{array}$ & $\begin{array}{l}.12 \\
.43\end{array}$ & 6 & $\begin{array}{ll}3 & ، \\
9 & \text { ، }\end{array}$ & $\begin{array}{l}\text { Sept. } \\
\text { Sept. }\end{array}$ & $\begin{array}{r}9 \\
13\end{array}$ & $\begin{array}{l}.05 . \\
.23 .\end{array}$ & "، & $\begin{array}{r}6 \\
10\end{array}$ & “" \\
\hline May & 14 , & .41 & $\begin{array}{l}\text { May } \\
\text { May }\end{array}$ & $\begin{array}{l}16, \\
19, \\
21\end{array}$ & $\begin{array}{l}.10 \text {. } \\
.10 \text {. } \\
10\end{array}$ & 66 & $\begin{array}{ll}2 & 6 \\
5 & 6 \\
7 & 6\end{array}$ & May & 21 & .32. & “6 & 7 & “ \\
\hline Dec. & 14, & .40 & $\begin{array}{l}\text { Day } \\
\text { Dec. } \\
\text { Dec. }\end{array}$ & $\begin{array}{l}21, \\
18, \\
22,\end{array}$ & $\begin{array}{l}.10 \\
.25 \\
.20\end{array}$ & “" & $\begin{array}{ll}4 & 4 \\
8 & 6\end{array}$ & & & & & & \\
\hline Jan. & 10 & .35 & Jan. & 16 & .30 . & “ & 6 & $\begin{array}{l}J_{\text {an }} \\
\boldsymbol{J}_{\text {an. }}\end{array}$ & $\begin{array}{l}14, \\
22,\end{array}$ & $\begin{array}{l}.12 . \\
.07\end{array}$ & "6 & $\begin{array}{r}4 \\
12\end{array}$ & ، \\
\hline
\end{tabular}




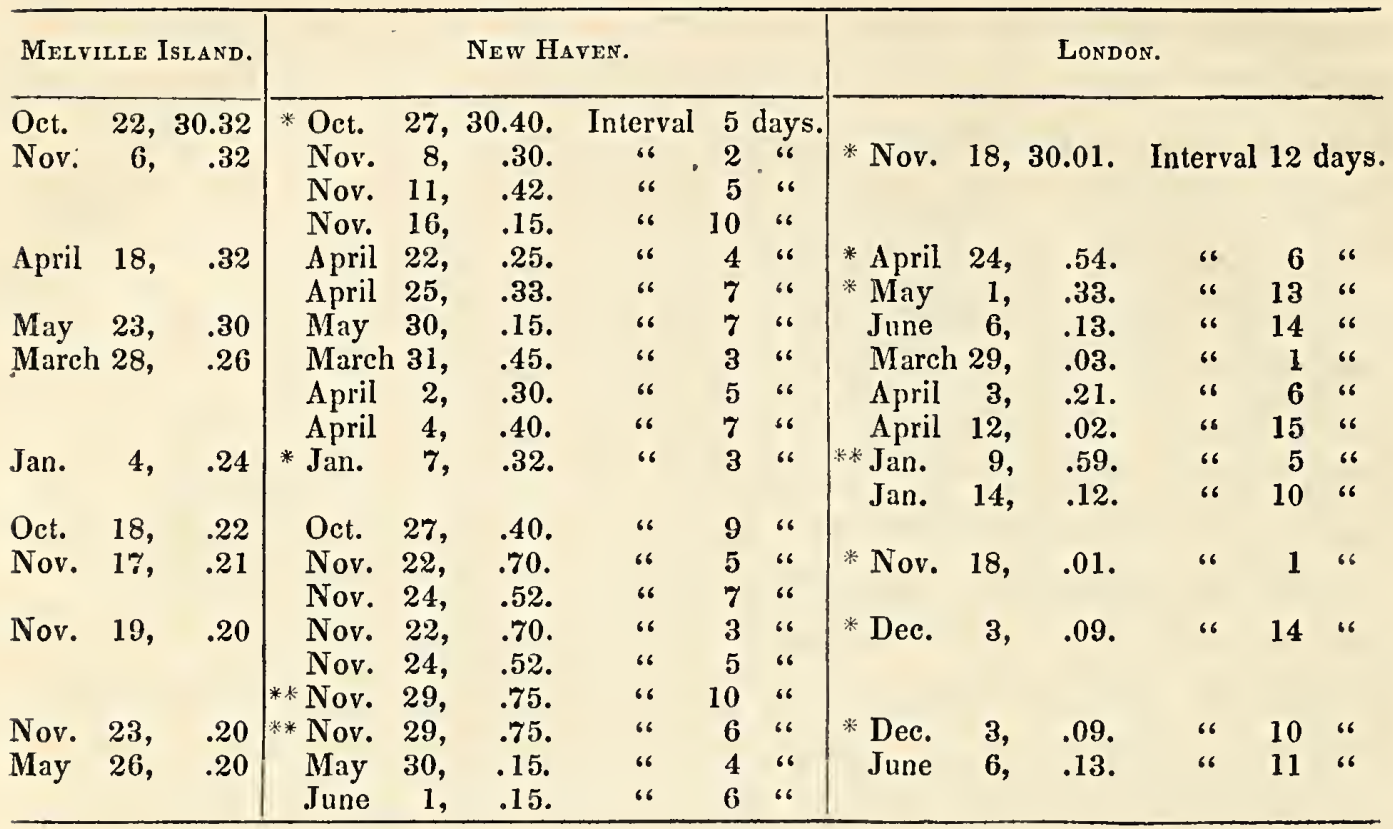

The observations distinguished by an asterisk were the highest of their respective months; those with a double asterisk the highest of the year. It will be observed that the principal New Haven maxima follow the Melville maxima generally at intervals of five or six days; and the London maxima follow at intervals of from five to ten days. To identify certainly a single wave would require simultaneous observations at numerous intermediate points; yet the preceding facts, taken in connexion with the increase of the barometric oscillation for December 20, 1836, from the southern part of the United States to the most northern station, seem to render it not improbable that the storm in question might have been experienced within the arctic circle.

By reference to the table on page 130 it will be seen that, with the exception of Twinsburgh, Bermuda, Halifax, and St. Johns, the barometric oscillation increased pretty regularly with the latitude. The observations at Twinsburgh being made with a wheel barometer, which, from the nature of the instrument, is susceptible of very little accuracy, I do not hesitate to reject them from this comparison. It will be seen that the oscillation at the three remaining stations was only about one-half what it was at the corresponding latitudes in the United States. This must be considered as evidence that the causes, whatever 
they were, which produced the oscillation, were now acting with diminished energy. The diminution was about one-half in less than two days. It might naturally be expected that the wave would go on diminishing until, by its insignificance, it should become insensible. What law this diminution would observe we are unable to say. For the sake of an estimate, however, let us take a simple supposition. The loss was one-half in two days. In two days more the last range might be reduced one-half; and again one-half in two days more. That is, in four days from St. Johns, the range would be in latitude $32^{\circ}, 0.11 \mathrm{inch}$; and in latitude $47^{\circ}, 0.22$ inch, a fluctuation too small to be traced with confidence. At the rate with which the wave travelled from Halifax to St. Johns, in four days more it would have passed somewhat beyond the Azores. But it will be observed that the velocity of the wave was sensibly reduced in travelling eastward. It had even become reduced to about one-half in two days in the latitude of Quebec. We might then expect the wave would become insensible before it reached the middle of the Atlantic.

But a remarkable storm was experienced over nearly the whole continent of Europe, about the 25th of December, and the opinion has been repeatedly expressed that this storm was identically the same with the one whose phenomena I am investigating. With the view of prosecuting this inquiry, I have collected all the European meteorological registers of this period in my power. Observations made at St. Petersburgh and Catherinenburgh were obtained from the library of the American Philosophical Society, by the politeness of $\mathrm{Mr}$. Vaughan, and copied for me by Mr. S. C. Walker. The latter place is in latitude $56^{\circ} 50^{\prime} \mathrm{N}$., and longitude $60^{\circ} 35^{\prime} \mathrm{E}$., and is eight hundred and thirteen English feet above the level of the sea. Observations for Brussels and Milan were furnished me by Mr. S. C. Walker, the latter being from the library of the High School Observatory in Philadelphia. The observations for Geneva, Zurich, and St. Bernard, were from the Bibliotheque Universelle, and copied by Mr. E. C. Herrick: those for London, Chiswick, and Boston, are from the London and Edinburgh Philosophical Magazine: those for Paris, from the Comptes Rendues des Séances de l'Academie; and those for Cadiz, in Spain, I obtained through our consul, Mr. Burton. The barometric observations I have projected in curves on Plate 2, a difference of an inch in the ordinates of the curves representing an oscillation of the barometer to the same amount. A bare inspection of this chart is sufficient to show that there were, at this pevII. - $2 \mathrm{M}$ 
riod, two distinct oscillations travelling in nearly opposite directions. One of these minima occurred at Cadiz, in Spain, on the 24th; passed Geneva on the afternoon of the 25th; London on the afternoon of the 26th; Boston by the morning of the 27th; St. Petersburgh and Catherinenburgh about midnight of the same day. The progress of this wave was almost due north, and at the rate of about twenty statute miles per hour. This certainly was not the same wave which passed over the United States, for the front of the latter was nearly north and south, while the front of the European wave was directed to the east and west, and was travelling northward.

The other barometric minimum was first experienced at St. Petersburgh on the 21st; at Catherinenburgh on the 22d; at Boston on the 23d; at Paris, Geneva, Zurich and Milan on the 24th; although at the latter place this oscillation is almost merged in the one before described. At Cadiz the wave is well nigh lost, but is, perhaps, barely discernible on the 27th and 28th. This wave, then, travelled nearly from north to south, inclining, however, to the west, and at the rate of about seventeen miles per hour. It is not, perhaps, equally clear that this wave cannot be identified with that of the United States. If we draw upon the globe lines representing the fronts of these waves, as I have done upon the accompanying chart, we shall find that they may be joined by a line of no very great curvature. Nevertheless, the fronts of both of the waves are curved, particularly the European wave, and when joined they make a curve with at least two points of inflection, as in the annexed diagram; the black line on the left hand representing the American, and the other the European wave. The appearances of the curves seems very clearly to indicate two distinct waves. If further confirmation were needed, it may be found in the course of the winds, which exhibited very different movements in Europe from what they did in the United States. As, however, I have not proposed to enter into any extended investigation of this European storm, and have only alluded to it for the sake of ascertaining whether it could be identified with that in America, believing that the evidence already presented will be conclusive to most minds, I think it unnecessary to adduce any further observations. I arrive, then, at the conclusion, that the storm of December 20th did not extend to the other side of the Atlantic.

I have made great inquiry for the log-books of vessels at this time on the 
Atlantic, but with indifferent success. 'I have found no barometric observations, and few log-looks of the common kind. The New York packet ship Hibernia left Liverpool December 20th. The following extract from her logbook gives some information of the weather which prevailed at that time on the Atlantic. For the sake of comparison I have placed by the side the winds as observed at Brussels.

\begin{tabular}{|c|c|c|c|c|}
\hline \multicolumn{4}{|c|}{ Ship Hiberkia. } & Brussels. \\
\hline $\begin{array}{r}\text { Dec. } 23, \\
24, \\
25, \\
26, \\
27, \\
28, \\
29, \\
30,\end{array}$ & 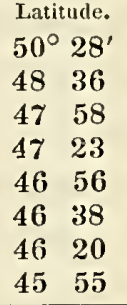 & $\begin{array}{cr}\text { Longitude. } \\
9^{\circ} & 9^{\prime} \\
14 & 36 \\
19 & 58 \\
23 & 40 \\
27 & 30 \\
32 & 6 \\
33 & 27 \\
34 & 3\end{array}$ & $\begin{array}{l}\text { Wind. } \\
\text { W.N.W.; N.W.; N.; showers. } \\
\text { N.E.; N.E.; showers of hail. } \\
\text { N.E.; E.N.E } \\
\text { N.E.; N.N.E.; showers. } \\
\text { N.E.; E.N.E.; E. } \\
\text { N.E.; E.N.E.; showers. } \\
\text { N.E.; E.S.E.; S.E. } \\
\text { Calm. }\end{array}$ & $\begin{array}{l}\text { N.; N.; N.; snow. } \\
\text { N.E.; N.E.; snow. } \\
\text { N.E.; N.E.; snow. } \\
\text { N.E.; N.E. } \\
\text { N.E.; N.E.; snow. } \\
\text { N.E.; E.N.E.; snow. } \\
\text { N.E.; N.E.; snow. } \\
\text { N.E.; N.E. }\end{array}$ \\
\hline
\end{tabular}

The uniformity in the direction of the winds shows that the Hibernia experienced the same kind of weather which prevailed in Europe up to the 29th of December, when she was in the middle of the Atlantic, and the American storm, if felt at all, ought already to have passed her. I have sought to procure some meteorological register from the Azores. The following extract, furnished by our consul, Mr. Dabney, is all I have been able to obtain. It exhibits the mean temperature of the respective days at Fayal.

$\begin{array}{rllllllll}\text { Dec. } 23 & 24 & 25 & 26 & 27 & 28 & 29 & 30 & 31 \\ 63^{\circ} & 64^{\circ} & 61^{\circ} & 63^{\circ} & 62^{\circ} & 67^{\circ} & 57^{\circ} & 57^{\circ} & 57^{\circ}\end{array}$

Here is exhibited a striking depression of the thermometer on the 29th. This may, perhaps, be ascribed to the influence of the American storm, which had just reached the Azores. A like depression of the thermometer, however, accompanied the European storm; and from the above observations of the $\mathrm{Hi}$ bernia, the latter influence would seem to have been the one chiefly, if not exclusively, felt. My conclusion, then, from this investigation is, that the eastern limit of the storm of December 20th cannot be placed beyond the middle of the Atlantic. The storm was probably sensible over seventy degrees of longitude and forty of latitude. 
Having given all the information I have been able to collect respecting the storm, and assigned, as far as practicable, its limits, I proceed to analyze more minutely its phenomena. Let us take, then, first, the observations of the wind. In making this comparison, certain general principles should be borne in mind. One is, that the direction of the wind is liable to be sensibly influenced by the inequalities of the surface of the earth. In a shallow stream of water, flowing over a rocky bottom, the course of the particles of water is often very devious. An effect similar in kind, though much greater in degree, must be expected from an elastic fluid like air. This is strikingly exhibited in the narrow and straight streets of cities, with high buildings on each side. The wind must here blow in the direction of the streets, or not at all. So, also, a mountain gorge; the straight bed of a river with high banks; the shore of a lake, or the ocean; or a mountain ridge might be expected sensibly to influence the direction of the atmospheric current. To this cause is doubtless to be ascribed the fact, that at stations very moderately removed from each other, the prevalent winds often differ sensibly in direction.

Again, the direction of the wind is exceedingly variable. I mean that its direction varies not merely from day to day, and from hour to hour, but from minute to minute, and from second to second. When the wind is at all fresh, it is rare that it blows sensibly from the same direction for five successive seconds. I have been the more struck with this fact from having a vane attached to a revolving shaft, to which is secured a graduated circle. The precise amount of the oscillations is thus easily measured. I am accustomed, at each observation, to note the extreme excursions during an interval of about five minutes. This range of the vane may be termed a measure of the variableness of the wind, and from an average of the year, does not differ much from fifty degrees. In repeated instances it has amounted to ninety, and even more, degrees. Now, one who judges of the direction of the wind from a single glance at a vane, is liable to mistake the mean direction by twenty-five or thirty degrees, because the vane, at the instant observed, may point thus much aside of its mean position. To this add the probable error of judgment when angles are estimated entirely by the eye, and it will not appear strange if two individuals, neither of them particularly careless in observing, should, at the same place, and at the same hour, sometimes differ by forty-five degrees in their estimate of the wind's direction. Indeed, at five-sixths of the stations from which ob- 
servations have been received, this appears to be the smallest fraction ever recorded. Add to this that the observations are generally taken but twice a day, and the precise hour to which the observation corresponds is seldom given, and we shall be prepared to expect considerable irregularity in comparing the observations at a hundred different stations. Finally, it is but reasonable to bear in mind that in the table of winds which I have given there may be actual errors of transcribing. The materials from which the table was prepared are copies, most of them at second hand, from the original records. In transcribing such a list of unmeaning letters, where the copyist can receive no assistance from the context to guide his judgment, slips of the pen are particularly liable to occur.

I trust it will not be inferred from these remarks that I have a theory of winds to which all the observations are to be made forcibly to conform, and that whatever seems obstinate is to be pronounced an error of observation. I wish merely to show that we should look at the general or average tendency of the winds at the several stations, and when one observation differs essentially from all the rest, it is not unphilosophical to regard it with distrust. That these remarks are not uncalled for will appear evident from comparing the different registers kept at almost identically the same station; for example, the two at St. Louis, and that at Jefferson Barracks; those at St. Augustine and Fort Marion; and those at New York, and its immediate vicinity.

It may be well to enumerate here the principal known causes of wind. It is believed that winds may commonly be referred to one of the three following causes, viz:

I. Inequality of atmospheric pressure.

II. Unequal specific gravity of air.

III. Rotation of the earth.

Conceive two vertical columns of air connected by a horizontal canal. If the weight of one column exceeds that of the other, it must preponderate. The wind, therefore, must blow from places where the barometer is highest, towards those where it is most depressed. Moreover, if the two columns of air supposed be of equal weight, but unequal specific gravity, there will be effected a new distribution of the particles of the two portions. The denser will flow under and displace the lighter. This inequality of specific gravity may arise either from a more elevated temperature or an excess of aqueous vapour. Even VII. $-2 \mathrm{~N}$ 
then, though the barometer may indicate every where the same pressure, the wind will blow, at the surface of the earth, from the colder to the warmer station; from the one where the dew point is lowest, to that where it is highest. In the upper regions of the air the current will, for the same reason, be reversed. The rotation of the earth is indirectly one of the most powerful causes of wind. Of itself it would produce no wind. When the earth first began to revolve upon its axis, the atmosphere, it may be supposed, would be left behind, and a wind would result, blowing with the velocity of the earth's motion. By friction upon the earth's surface, the air would, however, soon acquire the same motion with that part of the earth upon which it rested, and a universal calm would result as truly as if the earth were at rest. If authority is needed in support of this conclusion, we have that of Laplace. The earth's rotation, then, is not an independent cause of wind, although some have entertained a contrary opinion. But when one of the other named causes would alone produce a south wind in northern latitudes, the earth's rotation converts it into a south-west wind; and in like manner a north wind is converted into one from the north-east. Several other causes of wind might be enumerated, but it is believed that their action is comparatively feeble and unimportant.

Bearing in mind these preliminary principles, let us proceed to analyze the observations of the wind on pages 137-139. To do this the more conveniently, I furnish myself with a large number of small bits of paper, each having the figure of an arrow, and spreading out before me a map of the United States, I place at each station an arrow, representing the wind's direction for the period under comparison. I thus have a graphic representation of all the observations. Beginning, then, with the observations of the morning of December 18th, we find the barometer at an unusual height along the line of the Mississippi river, while, in the eastern states, it was quite low, but rapidly rising. The wind, at places east of Detroit, we find very uniformly blowing from the west. Where there is a deviation from this rule, it is usually to the northwest; and in one case only, Alleghany Arsenal, was the wind from the north. Near the southern border of the United States the wind was from some northern quarter, except at Natches, where it was east. The rise of the barometer which was experienced in the United States was nearly insensible south of the parallel of $28^{\circ}$, and hence a tendency of air in that direction. Along the valley of the Mississippi the barometer was at its maximum; the winds consequently 
were light, and their directions very various. More usually they were from the west, the quarter from which they had blown with great strength the day previous; but at a few stations they had already changed to the south and east, which was soon to become the prevalent direction; for it appears there was now a barometric minimum, not far to the west, towards which the whole atmosphere soon precipitated itself with great violence. In the afternoon of the 18th there was no change in the wind's direction at any station east of Detroit, nor any change of importance on the southern border. On the north-west the wind generally veered round more to the south, the cause which I have already assigned becoming now more sensible in its operation.

On the morning of the 19th, the wind, at places east of Baltimore, was still from the west. Albany furnishes the only exception to this remark, and here the wind is from the south. On the southern border the wind still blew from the north. At Picolata only was it from the east. In the western and northwestern states it was from the south. To this there was but one exception, at Fort Brady, where the wind was north-east. The more general tendency was from the south-east. A very instructive phenomenon is here exhibited. The barometer was at its maximum height on a line passing north and south, nearly through the centre of the United States, and the wind accordingly blew outward from the centre every where upon the borders. I do not mean precisely in the direction of radii from one point, but still decidedly outward; and there is but one palpable exception to this remark, namely, at Alleghany Arsenal, where the wind is reported from the north. Thus, on the eastern border, the prevalent direction was westerly; on the southern, northerly; on the western, south-easterly; and on the northern, southerly. These currents could not be maintained without producing a rapid drainage of air from the United States, unless there were some means of compensation. In point of fact, the drainage was not very rapid, as is shown by the barometric observations, and the required compensation we shall find in the upper current of the atmosphere. The winds of which I have been speaking were surface winds, reaching to only a moderate elevation, and above them flowed the usual upper current from the west. This might have been safely presumed in the absence of all testimony. The fact was, however, observed at Springfield, Syracuse, and New York, the only journals which noted at this time the direction of the clouds. The drainage from the lower currents was, however, somewhat more rapid 
than the supply from the upper, and the barometer began slowly to descend. On the afterrioon of the 19th the changes in the direction of the wind were very slight. At Fort Brady the wind changed from north-east to south-east, conforming now to the general direction of the winds in that quarter.

On the morning of the 20th the barometric maximum passed through the eastern extremity of Maine. The winds in the eastern states were accordingly light, and exceedingly variable. At about half of the stations, however, the wind was from the south, and at about one-half of the remainder it was southwest. The irregularity at the remaining stations I ascribe to the lightness of the wind, and to the fact that the influence of the barometric minimum at the west was just beginning to be felt, but had not yet had time to impress upon the winds any strong and steady impulse. On the southern border the winds generally continue to blow from the north. The barometric minimum now coincides nearly with the bed of the Mississippi river. Upon the west of this line, the wind blows from the north and north-west; upon the east side it blows from the east, south, and south-east. The winds in this section blow with great strength, and their directions, as might be expected, are far more regular and uniform. By the afternoon of the 20th the line of barometric minimum had advanced farther to the east. The number of stations west of this line at which the wind now blew from the north and north-west was increased. In the eastern states the general direction of the winds was substantially the same as in the morning. The wind at New Bedford and Halifax, the only stations in this section at which, in the morning, it blew from the north, now blows from the south. Oxford and East Hampton were the only stations, in the morning, at which the wind blew from the north-west. At the former of these it is now south, and at the latter south-west. On the eastern section of the storm the wind now every where, with but a few trifling exceptions, blows from some southern quarter.

On the morning of the 21st the barometric minimum had arrived nearly at New York city. In all the western and middle states the general direction of the winds is from the west and north-west. At a few places it is north, and at a few others south-west. But no where is it from the sculh, south-east, or east, and at only one station, Jefferson Barracks, from the north-east. Even this observation may be suspected to be a mistake, or must be ascribed to local situation, when it is found that at St. Louis the wind was from the west. The 
mean of all these directions is about N. $74^{\circ} \mathrm{W}$. On the southern border, also, the prevalent direction is north-west, although at two stations it is represented as inclining to the east. On the east side of the line of barometric minimum, the prevalent direction is from the south-east. As the observations were not all made at the same hour, they are not strictly comparable; and it seems necessary to leave out of the account those which were made near the line of minimum, because we cannot know, except conjecturally, whether they were made before or after this line had passed. We thus obtain for the mean direction at the remaining stations about S. $5^{\circ} \mathrm{E}$. At a certain distance, however, from the line of minimum the courses are very uniformly south-east. As this line approached, the wind veers to the south, south-west, west, and north-west. In the afternoon of the 21st, the line of barometric minimum had nearly reached Boston, and the north-west wind had become the prevalent one throughout almost the entire United States. In the extreme west the wind had begun to moderate its violence, and at Fort Jesup it blew from the northeast; at Fort Gibson from the east; and at Jefferson Barracks from the southeast. These are the only easterly winds recorded any where upon the west of the line of barometric minimum. The only south winds were at Pomfret and Granville, in New York. All the other winds, eighty-one in number, were from some point between the north and south-west; and their mean direction about N. $70^{\circ} \mathrm{W}$.

On the 22d the north-west wind was almost every where the prevalent one, particularly in the eastern section of the United States, where it blew invariably from some point between the north and south-west. On the southern border it blew very uniformly from the north; and in the western states the winds were becoming more light and irregular, veering round to the south and south-east, as they had done three days previous.

From the preceding review it will be seen that, in the midst of much irregularity, there was a considerable degree of uniformity in the course of the winds throughout the entire period under examination. It blows, at first, fresh from the north-west; this wind moderates and veers to the southward; it changes by nearly a calm to some eastern quarter; blows fresh from the south-east, in some places a gale; veers rapidly to the south, south-west, west, and northwest, blowing all the time with great violence. After about a day, the northwest wind moderates into a calm, and is succeeded by a southerly wind. In VII-2 0 
order to present these changes more palpably to the eye, $I$ have drawn upon the chart arrows, representing the direction of the wind for the forenoon of the 21 st, the length of the arrow being intended to be proportioned to the strength of the wind. These observations were not all strictly cotemporaneous; and hence arises some confusion in the course of the winds near the line of barometric minimum, particularly in the state of New York. It cannot, however, fail to be perceived that, at places moderately removed from each other, the wind blew from quarters almost diametrically opposed. At a little distance from the line of barometric minimum, on the east, the wind was from the south-east, while, on the west, it blew from the north-west. These were both violent winds, whose velocity, probably, could not be estimated at less than forty miles per hour. But how is it possible for two winds, not far separated from each other, to blow violently towards each other for hours, and even days, in succession? Let us make a simple numerical estimate. The wind blew from the north-west at least forty miles per hour. This gives a progress due east of more than twenty-eight miles per hour, and is fully equal to the average progress of the barometric minimum. This atmospheric wave, then, progressed with not far from the velocity with which the wind was actually observed to blow. But, in order to allow an opportunity for this onward progress, the wind in advance of this wave must retire, and that with the same velocity with which the north-west wave approaches. There seems no other possible supposition, unless the north-west wind flowed under the opposing wind. But what was the motion of the air in advance of this wave? About six hours in advance, it blows from the south-east; then, for three or four hours, it blows nearly from the south, and the entire change from south to north-west occupies only from one to two hours. The whole body of air in advance of this wave is moving, then, in almost exactly an opposing direction; whereas, as I have already stated, it ought to move in the same direction, in order to allow the wave's onward progress. The conclusion is inevitable; the north-west wind displaces the south-east one by flowing under it. I can think of but one mode in which any one can imagine it possible to evade this conclusion. The wind changed from south-east to north-west by the south-west. Some might fancy, therefore, that this south-west wind might furnish the necessary vent for this surplus air. But this south-west wind seldom blew an hour at any one place. Now, the phenomena which I have described were occurring simultaneously 
throughout the entire length of the United States, a distance of at least twelve hundred miles, and probably much greater. In order, then, that the southwest wind might drain off this vast torrent from the south-east, it would need to blow continuously for at least thirty hours with the velocity observed. And even on this supposition the south-west wind would only drain off the southeast, so as to prevent its advancing. But we have already seen that it must recede with the same velocity as that with which the opposing wave advances. I might call to my aid here, if necessary, the observations of the thermometer, but it would be superfluous. The case, to my.mind, is perfectly made out. This south-east current found its escape by ascending from the surface of the earth. Having quit the surface, it might either flow on in its first direction over the north-west current, or it might be entirely driven back over the southeast current; or both of these motions might exist simultaneously. When we come to consider the cause of the rain, we sliall be able to judge of the probability of these several suppositions.

If a south-east current should, pass a north-west one by blowing over it, the wind, to a stationary observer, would seem to change its direction by a calm. But if one were S. S. E. and the other W. N. W., as was nearly the case in the present instance, the wind would veer rapidly from one quarter to the other, passing through each of the intermediate points. The two currents must necessarily influence each other to some extent. As the north-west wind approached, the south-east would feel its influence, and begin to veer to the south. At a certain instant the two would exert equal power; and the direction of the particles of air would be precisely intermediate between those of the two great currents. Presently the second current would predominate, and, in a short time, the influence of the first would entirely disappear.

The question naturally arises, What produced this southerly wind throughout a territory so extended? The atmosphere is always warmer in the southern states than in the northern; why, then, should not a current always set from the north? There is no doubt, I think, that throughout this entire region the general progress of the atmosphere near the surface of the earth is towards the south. Not that the wind will necessarily blow a greater number of days in a year from the north than from the south, for the northerly winds are ordinarily far the most violent. One cause of southerly winds is found in the upper current, which, in these latitudes, blows from a point a little south of west. This 
wind, by friction upon the lower stratum, and by gradual subsidence into it, tends to impress upon the lower current its own direction. This accounts, in. part, for our westerly and south-westerly winds, but would not explain the south-east wind of the storm in question. The true explanation of this phenomenon is, I think, found in the fact that the greatest depression of the barometer was at some point north of the United States. The greatest observed. depression was at Quebec; and it is not improbable that the absolute minimum is to be found still farther north. We should expect a prevalent tendency of the winds towards this point of greatest depression; that is, in the United States, in front of the storm, we should expect a south-east wind, and to the north of the storm's centre, a north-east wind. I have been unable to obtain any observations for testing the truth of this last conclusion.

I come now to inquire for the cause of the rain. Rain is always owing to one cause, namely, a sudden reduction of the temperature of the atmosphere below the dew point. We run no risk in always assigning this as the immediate cause of rain. But how is this reduction of temperature effected? It may occur in a great variety of ways, among which are the following:-

I. Radiation.

II. Warm air coming in contact with cold earth or water.

III. A warm current coming in contact and mingling with a cold one.

IV. Air suddenly transported into elevated regions.

It is doubtful whether the first of these causes ever produces rain, for the reduction of temperature is too gradual. It is very common for the thermometer to sink during the night below the dew point of the preceding evening, and without any change of wind; yet not only no rain follows, but the atmosphere may remain perfectly transparent the whole time. Such circumstances produce a most copious dew, but seldom if ever rain.

The second cause is one which is often observed, but ordinarily produces merely a fog. Thus the warm air from the gulf stream rolling over the cold banks of Newfoundland produces the densest fogs; and in winter, the air from the sea flowing in upon the frozen earth has its moisture abundantly condensed. Yet the reduction of temperature effected in this way is also so gradual, it is believed never to produce any considerable rain.

The third cause, though very similar in principle to the second, is believed to be more efficient than either of the preceding, because it will produce $a_{4}$ 
more sudden change of temperature. The phenomenon, moreover, of atmospheric currents flowing one over the other in different directions may be observed almost every day of the year. But the fourth cause named, admitting its existence, must be allowed to be by far the most efficient of all. For the reduction of temperature may be conceived to be effected with almost any degree of suddenness, and to any extent. Thus, in midsummer, air with a dew point of $80^{\circ}$, being suddenly elevated two or three miles above the earth's surface, would, from change of temperature, lose almost the totality of its vapour. By supposing some cause which should continually renew the operation over a limited locality, we could account for the most violent and abundant rains on record. This case, therefore, demands particular consideration. This effect might be produced, 1. By a horizontal current impinging upon the side of a mountain. The current might thus be forced up to an elevation, where it would experience a very great and sudden reduction of temperature, and a portion of its vapour be instantly precipitated. 2. A large body of air might be suddenly and mechanically elevated by a volcanic eruption. The direct effects of these two causes must, however, be quite local. If they ever influence distant stations, it must be indirectly, by means of currents here set in motion. 3. Air may be elevated by a whirlwind; for even in horizontal whirlwinds there is ordinarily, if not always, an upward motion in the centre of the vortex. 4. When a hot and cold current, moving in opposite directions, meet, the colder, having the greatest specific gravity, will displace the warmer, which is thus suddenly lifted from the surface of the earth, is cooled, and a part of its vapour precipitated. This is a cause which may operate in any locality, and with almost any degree of energy. It is believed, therefore, to be, at least in this latitude, the most common cause of rain. Let us now review the circumstances of the rain which fell during the period under examination. This occurred during the winter, and with a southerly wind. We liave here, then, the second cause for the reduction of atmospheric temperature, operating under the most favourable circumstances. Yet the precipitation arising from this cause must begin at the surface of the earth, and proceed very gradually. But in the present case the rain came from a considerable elevation, and poured down in torrents. Although, then, this be admitted as a cause of rain, I cannot regard it as the main cause, nor any thing more than a very feeble auxvII. -2 P 
iliary. Can the third cause be the true one? We have, in the present case, a warm current from the south, and, without doubt, a little above it, a cold current from the west. The consequence would be, a certain amount of precipitation from the partial mingling of these two currents where they came in contact. The whole amount of air which could be cooled in this way is very small, and the consequent precipitation would be only a small fraction of that which was observed. Let us, then, inquire if the fourth cause could be supposed to operate. We have already shown from the observations of the wind, without the aid of any hypothesis, that the southerly current must have disappeared by being elevated into the upper regions of the air. This I regard as a necessary deduction from the observations. We find, then, a warm current suddenly cooled, and its moisture must, of course, be in part precipitated. I find by computation, that if the entire atmosphere, saturated with moisture at the temperature of $70^{\circ}$, be cooled $5^{\circ}$ 7

\begin{tabular}{|c|c|c|c|}
\hline & 60 & " & one inch of \\
\hline & 50 & 10 & water will be \\
\hline “ & 40 & 16 & precipitated. \\
\hline " & 30 & 25 & \\
\hline
\end{tabular}

But the average amount of water which fell throughout the United States was somewhat less than one inch. The cause we have assigned, then, seems adequate to account for the phenomena. We have simply determined, as yet, that the south-east wind must have disappeared by being lifted from the earth's surface. But in what direction did it continue to move? It might be supposed to continue on its course towards the north-west, above the other current, or to return towards the south-east. Being a current of more than a thousand miles in breadth, we can hardly suppose it to escape either by the northeast or the south-west. Did it, then, continue its direction towards the northwest? We should then have a warm and moist current flowing at a great elevation over an exceedingly cold one. The consequence would be, that its moisture would not only be precipitated, but frozen, and would descend to the earth in the form of snow or hail. This is conformable to observation. Snow and hail did fall at nearly all of the northern stations, after the north-west wind set in. But the amount was small; much less than must necessarily result if this entire southerly wind had flowed over the northerly, and had its moisture 
precipitated by it. Still, it seems probable that a part of this southerly wind did continue on its course, and produce the snow which was observed to fall. I infer that the current was mainly turned back upon itself, so that the moisture, as fast as precipitated, fell through the lower current, still blowing from the south-east. My idea may, perhaps, be best illustrated by a diagram.

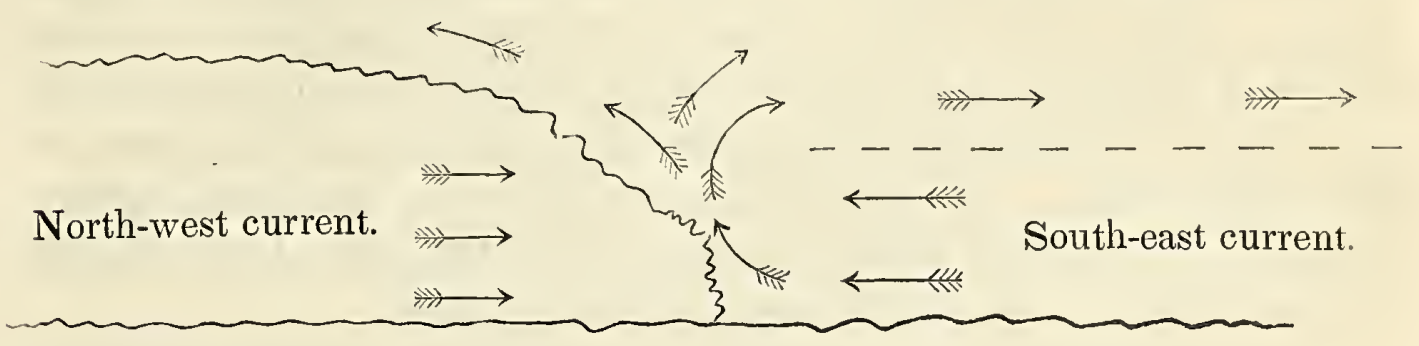

A part of the moisture of this south-east current might be frozen from the cold of elevation, even if it were driven back in the direction from which it came. But, falling through a warm stratum, before it reached the earth's surface it would be entirely melted. At several stations hail fell in small quantities very soon after the wind changed. This might be owing to the moisture of the warm current suddenly condensed by contact with the cold one, and sustained by this upward motion, until the frozen drops had acquired the size actually observed, which in no case was very great.

Why more rain fell at some stations than at others only moderately distant I cannot certainly say. The causes, doubtless, were local, and it would be unsafe to assign particular reasons without a good knowledge of the localities. Such an effect, however, might be produced by a hill of moderate elevation, which would raise the lower current, and, consequently, the returning upper current, to an unusual elevation, producing a corresponding depression of temperature.

The observations of the thermometer on pages 131-133 are believed to present nothing very difficult of explanätion. That the temperature should rise under a southerly wind was to be anticipated. The wind blew from a southern quarter more than twelve hours, in which time it probably travelled nearly five hundred miles, or, making allowance for the obliquity of its course, between four and five degrees of latitude. The difference of temperature corresponding 
to this difference of latitude, for winter, in the United States, is about ten degrees. But the temperature of the air generally rose more than this number of degrees above the mean. Moreover, there prevailed in the northern states a vast body of snow and ice, which rapidly absorbed the caloric of this southern current. The explanation, then, is insufficient. We shall find an additional cause for this elevated temperature in the abundant precipitation of aqueous vapour. When vapour becomes reduced to the liquid state, it gives up a large amount of latent heat, which will, of course, be taken up by the surrounding air. The temperature of the eastern states was found to be a little greater than that of the western. At the former, the southerly wind came from the ocean, which, in winter, has a higher temperature than the land. It is not clear, however, that more rain fell in one section than the other.

That the north-west wind was cold is not remarkable. It came from a high latitude, where the prevalent temperature is, probably, far below zero. Its severity, however, became somewhat tempered in its progress, the mean of the minima at the eastern stations being fourteen degrees higher than at the western.

I come now to the phenomenon probably the most difficult of all to be explained, namely, the oscillation of the barometer. For the movements of this instrument various causes have been assigned, some of them so unphilosophical that it is really astonishing that they could ever have been seriously proposed by intelligent men.

1. The oscillations of the barometer have been ascribed to the destruction of large masses of air in the higher regions by electricity. The supposition is too gratuitous to deserve serious consideration.

2. They have been ascribed to the diminished pressure resulting from the loss of rain. But the amount of rain which fell in the case under consideration would be balanced by a column of mercury about one-fifteenth of an inch in height.

3. Heat, by expanding 'a column of air, causes it to ascend to a greater height, and thus changes its centrifugal force arising from the earth's rotation. This cause is too insignificant to produce the effect in question.

4. They have been ascribed to the attractions of the sun and moon. Laplace estimates the greatest oscillation of the barometer due to this cause to be, at the equator, 0.025 inch. 
5. Leslie ascribes them to the centrifugal force arising from violent winds. But, in the case of a hurricane, this would not produce an oscillation of the barometer amounting to the thousandth part of an inch.

6. The opposition of winds. This might produce a small movement of the barometer. We shall presently inquire whether this cause operated in the case under consideration.

7. The barometer has frequently been observed to fall under the influence of a whirlwind. But in the present case there was no whirlwind.

8. These oscillations have been ascribed to sudden changes in temperature and in the amount of aqueous vapour. An elevation of temperature of the entire atmosphere could not directly affect its pressure, for, in proportion as its density is diminished, its height will be increased. But if, by any means, a portion of hot air can be made to displace an equal bulk of cold air, the weight of the column must be diminished. It is obvious that this cannot be a state of permanent equilibrium; yet it is worthy of inquiry whether it may not temporarily exist under the influence of winds. On the 20th of December, 1836, the air over nearly the whole of the United States became unusually heated, and its specific gravity was, of course, diminished. If, then, the height of the atmosphere remains invariable, a diminution of pressure ought to be the consequence. But, although a fall of the barometer is usually accompanied by an elevation of temperature, the reverse is sometimes the case. Thus the fall of the barometer in Europe, which I have represented on Plate 2, and which, at most places, amounted to more than an inch, was accompanied by a steady fall of the thermometer. The barometer, in this case, fell in spite of the increased specific gravity of the air. We may naturally presume, then, that a change in the specific gravity of the air produces only a secondary effect on the oscillations of the barometer.

9. A wind blowing upward or downward would affect the pressure of the air. This is a cause whose existence we have proved in the case in question. Its effect upon the mean pressure of the air in the equatorial regions is unequivocally maintained in the Instructions for the British Scientific Expedition to the Antarctic Regions, recently prepared by the President and Council of the Royal Society, causing the barometer at the equator to stand permanently lower than in latitude $30^{\circ}$, by about a quarter of an inch. The asVII. -2 Q 
cending current of December 20th could not, however, exert any direct influence upon the barometer, except near the centre of the storm. To account for the entire oscillation, I think, we must admit another principle quite distinct in its operation.

10. Let a wind blow ever so violently over the earth's surface, and the diminution of gravity arising from the centrifugal force must be inconsiderable. But, imagine the different parts of the current to travel with unequal velocity, and there will arise a mechanical condensation, or rarefaction. When air is at rest, or in motion, with a uniform velocity, its particles are maintained at a constant distance from each other. But let the velocity of one section be increased beyond that of the succeeding, and the same particles of air are forced to fill a greater space. Such is the principle of the undulations which produce the sensation of sound. It appears to me that a similar effect must have been produced in the storm of December 20th. The southeast wind which accompanied the rain moved with an accelerated velocity. The particles, therefore, of air at one extremity of the current must have left those of the other extremity at an increased distance. Hence a mechanical rarefaction, and, of course, diminished pressure. The reverse effect must have taken place after the storm had passed. A north-west wind sets in with great violence. A vast body of air is precipitated towards the southeast. The partial vacuum which at first existed is very soon supplied. Yet, though the first impelling cause has ceased to act, the momentum of the excited current still urges it onward. The front of the wave is impelled by the momentum of the mass in the rear, and a mechanical condensation results, bringing, of course, increased barometric pressure. The cause, however, which produces this extraordinary rise, being temporary in its nature, soon ceases, and the barometer falls. The causes which I have here assigned for the oscillation of the barometer appear to me to be such as are known to be true, and that they are sufficient to account for the phenomena.

I have thus analyzed the phenomena of this somewhat remarkable storm, and given such explanations of them as have appeared to me most satisfactory. It is a most interesting and important inquiry, low far the conclusions at which I have here arrived may be safely generalized. I have already made some progress in this investigation; but as the present paper has now 
grown to an unexpected length, I reserve my remarks upon that point to some future opportunity. I trust it will not be inferred from my silence with respect to the labours of others in this important field, that I am wholly ignorant of them, or am insensible of their value. I have availed myself of the labours of others as far as was in my power. To have credited every suggestion to its original author would have been inconvenient, and generally superfluous, being found in most treatises on meteorology. I am happy, however, to express my particular obligations to the labours of Messrs. Redfield, Espy, and Col. Reid, and shall esteem myself well repaid if the present communication shall contribute something to the progress of that science which they have done so much to promote. 



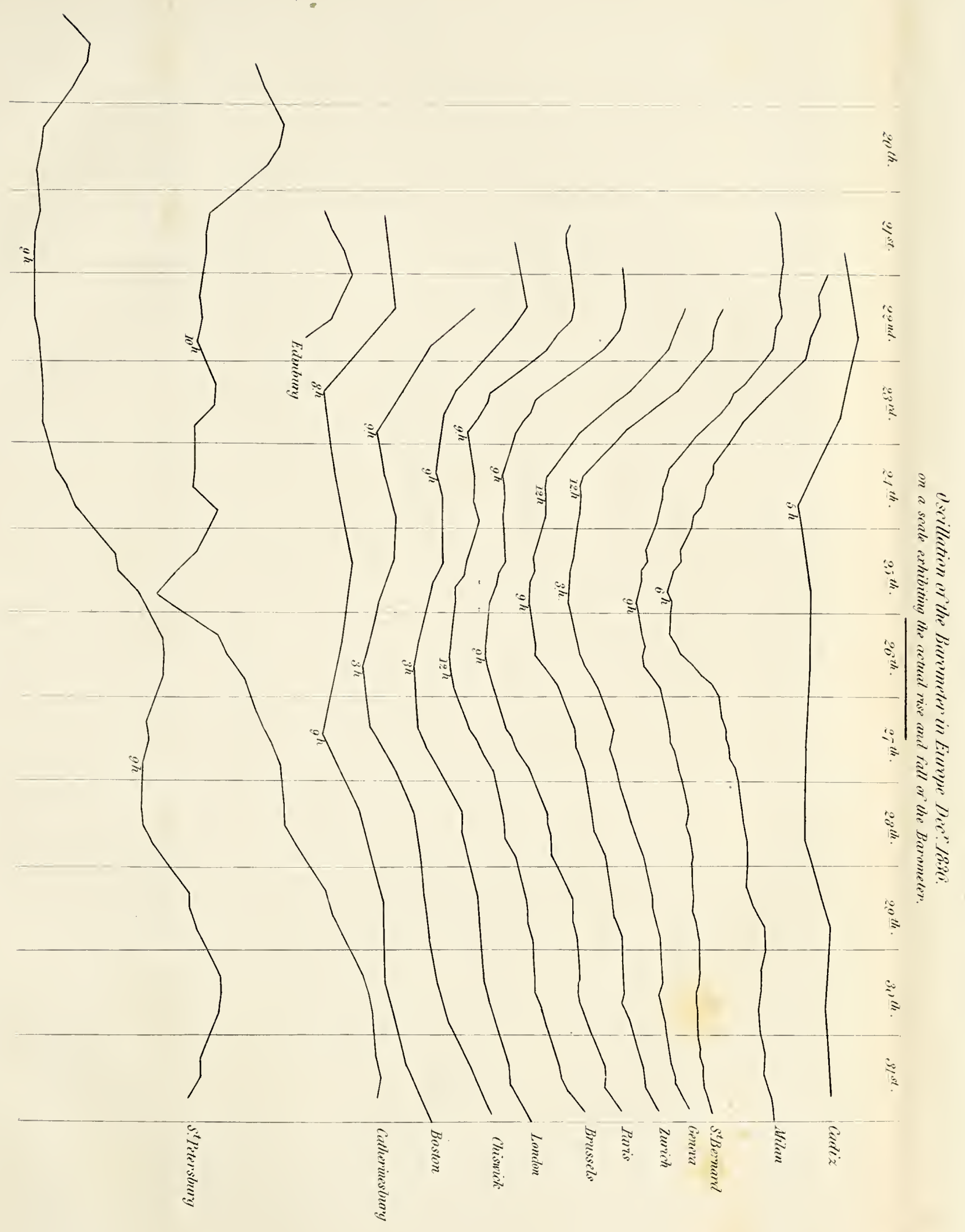




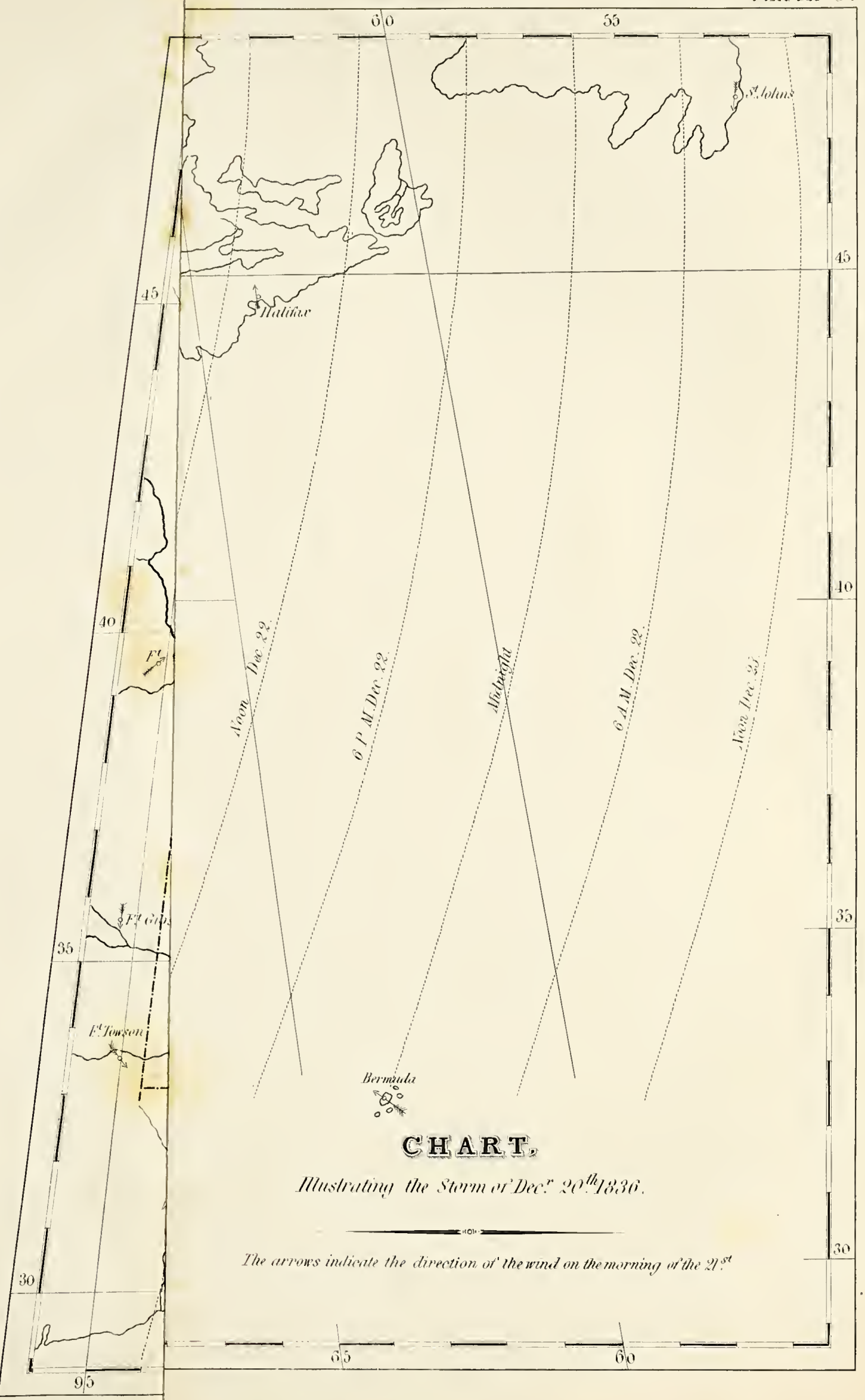





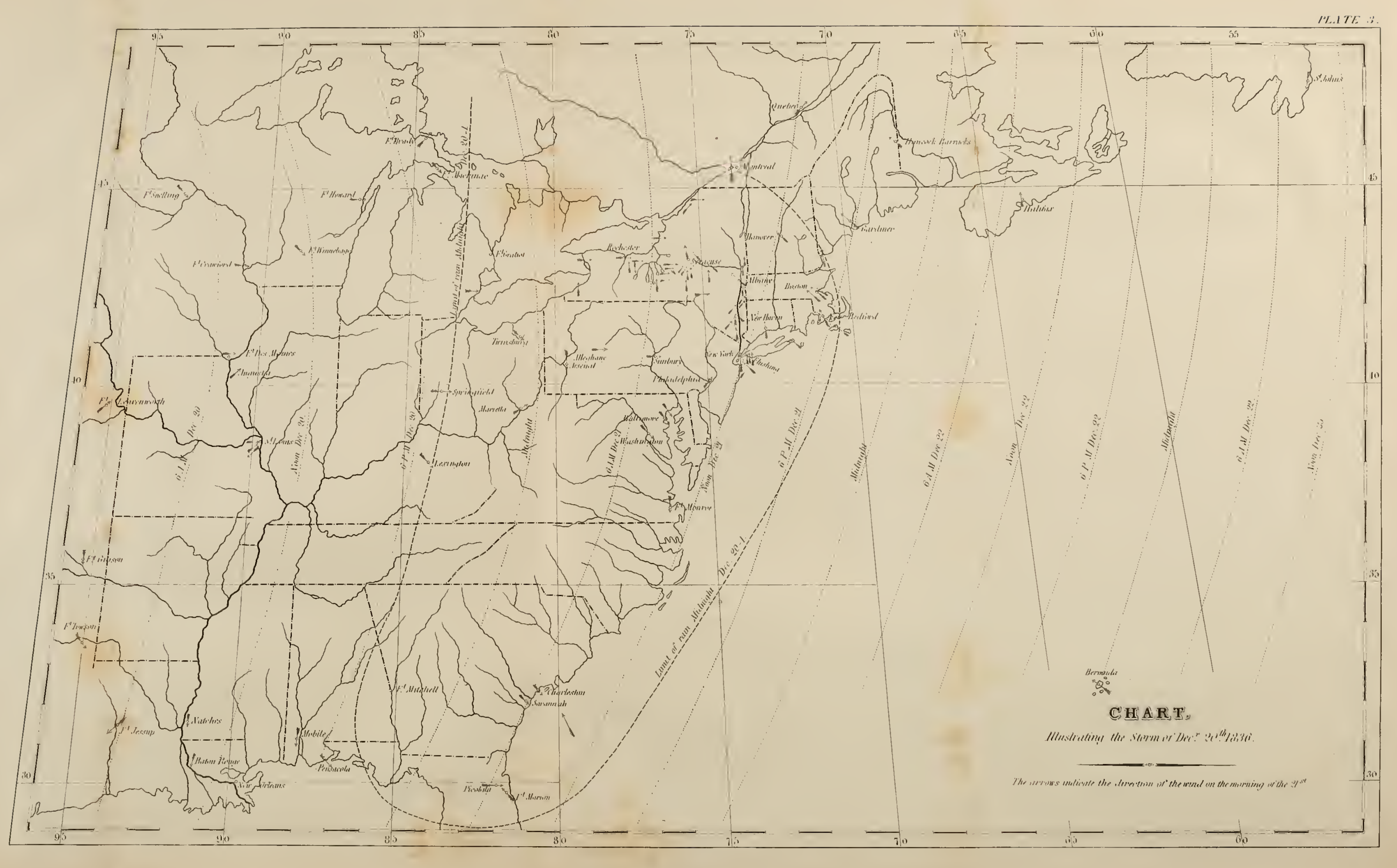




